\title{
EFFICIENCY AND EQUILIBRIUM WHEN PREFERENCES ARE TIME-INCONSISTENT
}

\author{
by
}

Erzo G J Luttmer

University of Minnesota and CEPR

and

Thomas Mariotti

London School of Economics and Political Science, Université de Toulouse (CNRS-GREMAQ) and CEPR

$\underline{\text { Contents: }}$

Abstract

1. Introduction

2. Efficiency in an Exchange Economy

3. Two Economies with a Sequence of Markets

4. Smooth Preferences

5. Concluding Remarks

References

Discussion Paper

No.TE/03/446

January 2003
The Suntory Centre

Suntory and Toyota International Centres for Economics and Related Disciplines

London School of Economics and Political Science Houghton Street

London WC2A 2AE

Tel.: 020-7955 6698 


\section{Abstract}

We consider an exchange economy with time-inconsistent consumers whose preferences are additively separable. When these consumers trade in a sequence of markets, their time-inconsistency may introduce a non-convexity that gives them an incentive to trade lotteries. If there are many consumers, competitive equilibria with and without lotteries exist. The existence of symmetric equilibria may require lotteries. Symmetric equilibria that do not require lotteries are generically locally unique. Allocations that are Pareto efficient at the initial date are also renegotiationproof. Competitive equilibria are Pareto efficient in this sense, and for generic endowments, if and only if preferences are locally homothetic. For non-homothetic preferences, the introduction of lottery markets has an ambiguous impact on the equilibrium welfare of consumers at the initial date.

Keywords: Dynamic inconsistency, competitive equilibrium, lotteries, generic inefficiency.

JEL Nos.: D50, D91.

(C) by the authors. All rights reserved. Short sections of text, not to exceed two paragraphs, may be quoted without explicit permission, provided that full credit, including (c) notice, is given to the source.

Contact address: Dr Thomas Mariotti, Department of Economics, London School of Economics and Political Science, Houghton Street, London, WC2A 2AE, UK. Email: t.mariotti@lse.ac.uk 


\section{INTRODUCTION}

There has been a recent upsurge of interest in models in which consumers have present-biased time-inconsistent preferences. This interest is motivated in part by introspection, by experiments, and by the possibility that certain types of behavior can be more easily understood using such preferences. ${ }^{1}$ Much of the literature has taken a partial equilibrium approach, focusing on deriving, at given prices, the implications of time-inconsistency for the behavior of consumers. ${ }^{2}$ In this paper, we examine the properties of competitive equilibria when consumers are time-inconsistent. Our aim is to describe the extent to which classical results on the existence and efficiency of competitive equilibria in an economy with a sequence of markets need to be modified when the usual requirement of time-consistency is dropped.

We consider a three-period exchange economy and adopt two important simplifying assumptions. First, we take preferences to be additively separable across time and states of the world. Second, we assume that all consumers discount future utilities in the same way, although their period utility functions may differ. A remarkable implication of these assumptions is that allocations that are Pareto efficient from the perspective of consumers at the initial date remain Pareto efficient at subsequent dates. This implies that the set of initially Pareto efficient allocations is the same as the set of renegotiation-proof allocations.

A complete set of markets open only at the initial date can be used to implement any allocation that is Pareto efficient from the perspective of consumers at this date. Since all choices are made at this initial date, time-inconsistency of preferences is irrelevant. We are interested instead in an environment in which markets are open in every period. We assume that a typical consumer correctly anticipates future prices as well as his or her own future behavior. Just as in the case of time-consistent preferences, this future behavior can be summarized by a value function defined over wealth saved by the consumer at the initial date. However, because of timeinconsistency, this value function need not be concave, even if the underlying period utility functions are. As a result, the demand correspondences of individual consumers may not be convex-valued. To guarantee existence of an equilibrium, we assume that

\footnotetext{
${ }^{1}$ Strotz (1956) and Phelps and Pollak (1968) are early authors who considered additively separable preferences exhibiting time-inconsistency. Laibson (1997) shows that partially illiquid assets may provide commitment to consumers with time-inconsistent preferences. Harris and Laibson (2001) study the dynamic choices of a consumer with quasi-hyperbolic preferences facing a constant riskfree interest rate and subject to borrowing constraints. Barro (1999), Krusell and Smith (1999), and Krusell, Kuruş̧u and Smith (2001) consider a version of the standard Ramsey growth model with time-inconsistent preferences. More generally, time-inconsistency has been used to model a wide range of problems involving self-control. See for instance Benabou and Tirole (2002), Carrillo and Mariotti (2000) and O'Donoghue and Rabin (1999a, 1999b). Gul and Pesendorfer (1999, 2001) propose a recursive approach to self-control problems.

${ }^{2}$ See, however, Kocherlakota (2001), Krusell, Kuruşçu and Smith (2001), Krusell and Smith (1999) and Luttmer and Mariotti (2000). But these papers do not allow for any heterogeneity in preferences.
} 
there is a continuum of consumers.

The possibility of non-concave value functions means that the resulting competitive equilibria may have to be asymmetric: identical consumers may be indifferent between several choices, and which choices they make is determined by the requirement that markets clear. We show that in such an equilibrium, price-taking consumers at the initial date have an incentive to pool their resources and run a lottery over the fraction of aggregate wealth each consumer receives at the second date.

To allow consumers at the initial date to exploit these perceived gains to trade, we introduce an additional market in which lotteries are traded. Given such a market, a symmetric equilibrium always exists, provided period utility functions are not asymptotically risk-neutral. In an example, we show that asymmetric equilibria and symmetric lottery equilibria can indeed occur. At the asymmetric equilibrium of an economy without lottery markets, the incentives to trade lotteries are unambiguous. But allowing such lotteries to be traded will affect equilibrium prices, and these price effects can hurt consumers at the initial date. As a result, the effect on welfare of consumers at the initial date of allowing trade in lotteries is ambiguous. In some examples, opening lottery markets helps, and in others it hurts consumers at the initial date.

The utility of a consumer at the initial date is affected by the behavior of the same consumer at all later dates. This can be viewed as an externality, and our examples confirm that the competitive equilibrium allocation of an economy with a sequence of markets, with or without lottery markets, need not be efficient. There is, however, an important special case in which the classical welfare theorems do apply to an economy with a sequence of markets. This is the case of homothetic preferences analyzed in Luttmer and Mariotti (2000). ${ }^{3}{ }^{4}$ We show here that the condition of homotheticity is necessary for the generic efficiency of the competitive equilibrium. We prove that for nowhere locally homothetic preferences, and for generic endowments, the set of competitive equilibria and the set of allocations that are efficient from the perspective of consumers at the initial date have an intersection that is of lower dimension than either set. Time-inconsistency distorts intertemporal marginal rates of substitution by a factor that depends on marginal propensities to consume. The linear consumption functions implied by homothetic preferences ensure that this distortion is the same across consumers, and this restores efficiency.

\footnotetext{
${ }^{3}$ This result does not even depend on the assumption of additive separability used in this paper. See Luttmer and Mariotti (2000b).

${ }^{4}$ Kocherlakota (2001) uses logarithmic preferences. Therefore, the competitive equilibrium will be efficient from the perspective of consumers at the initial date when there is a sequence of markets, just as it is when markets are only open at the initial date. But the intermediate case considered in his paper - some securities can only be traded at the initial date and cannot be borrowed against at a later date - generates a equilibrium that is not efficient.
} 


\section{EfFiciency in An ExChange ECONOMy}

We consider a three-period exchange economy with a finite number, $I$, of consumer types. There is a continuum of consumers of each type, and for notational simplicity we take this continuum to be of unit measure for every type. A single good is available for consumption in every period. For every $i$ and $t$, a consumer of type $i$ has positive endowments $e_{i, t}$ of this good in period $t$. Aggregate endowments in period $t$ are denoted by $e_{t}$. A consumer of type $i$ has preferences over non-negative consumption sequences $c_{i}=\left(c_{i, 1}, c_{i, 2}, c_{i, 3}\right)$ given by:

$$
U_{i, 1}\left(c_{i}\right)=u_{i}\left(c_{i, 1}\right)+\delta_{1} u_{i}\left(c_{i, 2}\right)+\delta_{2} u_{i}\left(c_{i, 3}\right)
$$

in period 1 , and by:

$$
U_{i, 2}\left(c_{i}\right)=u_{i}\left(c_{i, 2}\right)+\delta_{1} u_{i}\left(c_{i, 3}\right)
$$

in period 2. The subjective discount factors $\delta_{1}$ and $\delta_{2}$ are positive, and the period utility functions $u_{i}: \mathbb{R}_{+} \rightarrow \underline{\mathbb{R}}=\mathbb{R} \cup\{-\infty\}$ are assumed to be strictly increasing, continuous, and strictly concave. These preferences are time-inconsistent whenever $\delta_{1}^{2} \neq \delta_{2}$, with a bias toward the present if $\delta_{1}^{2}<\delta_{2}$. Note that, although the period utility functions $u_{i}$ may vary across consumers, the discount factors $\delta_{1}$ and $\delta_{2}$ are the same for all consumers.

Efficient Allocations A (symmetric, non-random) allocation in this economy is a vector $c \in \mathbb{R}_{+}^{3 I}$ of consumption sequences, one for each consumer type. An allocation is feasible if aggregate consumption at every date does not exceed aggregate endowments. Because preferences may change over time, there are several notions of efficiency that can be useful.

Definition 1 A feasible allocation $c$ is:

(i) Weakly Pareto efficient if there is no other feasible allocation $c^{\prime}$ such that $U_{i, t}\left(c_{i}^{\prime}\right) \geq U_{i, t}\left(c_{i}\right)$ for all $(i, t)$, and such that this inequality is strict for at least one $(i, t)$.

(ii) Date-t Pareto efficient if there is no other feasible allocation $c^{\prime}$ such that $U_{i, t}\left(c_{i}^{\prime}\right) \geq$ $U_{i, t}\left(c_{i}\right)$ for all $i$ and such that this inequality is strict for at least one $i$.

(iii) Renegotiation-proof if it is date-2 Pareto efficient and there is no other date-2 Pareto efficient allocation $c^{\prime}$ such that $U_{i, 1}\left(c_{i}^{\prime}\right) \geq U_{i, 1}\left(c_{i}\right)$ for all $i$ and such that this inequality is strict for at least one $i$.

The three definitions given here can be extended in the obvious way to asymmetric or random allocations. It is easy to see that, because of the strict concavity of $u_{i}$, random allocations can never be weakly Pareto efficient, date-t Pareto efficient, or renegotiation-proof. 
Beyond ruling out random allocations, weak Pareto efficiency imposes few restrictions on an allocation. Because preferences are additively separable and the horizon is finite, any (non-random) allocation that exhausts aggregate resources at every date is weakly Pareto efficient, even when preferences are time-consistent. ${ }^{5}$ Date- 1 Pareto efficiency is the natural notion of efficiency when consumers can commit to a sequence of consumption choices. When this is not the case, the set of renegotiation-proof allocations represents a notion of constrained efficiency: these allocations are efficient from the perspective of date- 1 consumers, subject to the constraint that date- 2 allocations are efficient. Clearly, if an allocation is date- $t$ efficient for both $t=1$ and $t=2$, then the allocation is renegotiation-proof. It turns out that all date- 1 efficient allocations are date- 2 efficient.

Proposition 1 The sets of date-1 Pareto efficient and renegotiation-proof allocations coincide.

Proof. Let $e=\left(e_{1}, e_{2}, e_{3}\right)$, and consider the set of feasible date-1 utilities:

$$
\mathcal{U}_{1}=\left\{U_{1} \in \underline{\mathbb{R}}^{I}: \exists c \in \mathbb{R}_{+}^{3 I} \text { s.t. } \sum_{i=1}^{I} c_{i} \leq e \text { and } U_{i, 1}\left(c_{i}\right) \geq U_{i, 1} \forall i=1, \ldots, I\right\} .
$$

Since the aggregate resource constraint is convex and the utility functions $U_{i, 1}$ are concave and continuous, $\mathcal{U}_{1}$ is a closed and convex set. Date- 1 Pareto efficiency of an allocation $c \in \mathbb{R}_{+}^{3 I}$ implies that $c$ belongs to the boundary of $\mathcal{U}_{1}$. By the separating hyperplane theorem, there exists $\lambda \in \mathbb{R}^{I} \backslash\{0\}$ such that $\lambda \cdot U_{1}(c) \geq \lambda \cdot U_{1}$ for all $U_{1} \in \mathcal{U}_{1}$, and, since $\mathcal{U}_{1}-\mathbb{R}_{+}^{I} \subset \mathcal{U}_{1}$, we must have $\lambda \geq 0$. In particular, $c$ solves:

$$
\max _{c \in \mathbb{R}_{+}^{3 I}}\left\{\sum_{i=1}^{I} \lambda_{i} U_{i, 1}\left(c_{i}\right): \sum_{i=1}^{I} c_{i} \leq e\right\} .
$$

Since the resource constraints are independent across time and preferences are additively separable, and since the discount factors $\delta_{1}$ and $\delta_{2}$ are the same across consumers, the solution to (1) can be obtained by solving:

$$
\max _{c_{t} \in \mathbb{R}_{+}^{I}}\left\{\sum_{i=1}^{I} \lambda_{i} u_{i}\left(c_{i, t}\right): \sum_{i=1}^{I} c_{i, t} \leq e_{t}\right\}
$$

for all $t$. This in turn implies that $c$ solves:

$$
\max _{c \in \mathbb{R}_{+}^{3 I}}\left\{\sum_{i=1}^{I} \lambda_{i} U_{i, 2}\left(c_{i}\right): \sum_{i=1}^{I} c_{i} \leq e\right\} .
$$

\footnotetext{
${ }^{5}$ This is no longer true if there is an infinite number of periods. For example, if there are two sufficiently patient types of consumers whose endowments oscillate in opposite directions, then it can be weakly Pareto improving to smooth the allocation. In an economy with a finite number of periods but multiple goods at every date, weak Pareto efficiency would only require that at any particular date, marginal rates of substitution for the goods at that date are lined up.
} 
Therefore, since $\lambda \geq 0$ and $\lambda \neq 0$, there exists no feasible allocation $c^{\prime}$ such that $U_{i, 2}\left(c_{i}^{\prime}\right)>U_{i, 2}\left(c_{i}\right)$ for all $i$. Using the fact that the $u_{i}$ are continuous and strictly increasing one can verify that this implies that $c$ is date-2 Pareto efficient.

It is easy to extend this result to multi-period economies in which consumers of type $i$ have preferences at date $t$ given by $\sum_{n=0}^{T-t} \delta_{n} u_{i}\left(c_{i, t+n}\right)$, with $T$ possibly infinite. Proposition 1 also holds under uncertainty if preferences after every history can be represented by an expected utility function using subjective probabilities that are updated using Bayes' rule. ${ }^{6}$

Different Discount Factors Things change when consumers have discount factors $\delta_{i, 1}$ and $\delta_{i, 2}$ that are not the same for all $i$. Let $c(\lambda)$ be a date-1 Pareto efficient allocation given a vector of Pareto weights $\lambda$ for date- 1 utilities. That is, $c(\lambda)$ solves:

$$
\max _{c \in \mathbb{R}_{+}^{3 I}}\left\{\sum_{i=1}^{I} \lambda_{i}\left(u_{i, 1}\left(c_{i}\right)+\delta_{i, 1} u_{i}\left(c_{i, 2}\right)+\delta_{i, 2} u_{i}\left(c_{i, 3}\right)\right): \sum_{i=1}^{I} c_{i} \leq e\right\} .
$$

For $c(\lambda)$ to remain Pareto efficient at date 2 , it must be that $\left(c_{2}(\lambda), c_{3}(\lambda)\right)$ solves:

$$
\max _{\left(c_{2}, c_{3}\right) \in \mathbb{R}_{++}^{2 I}}\left\{\sum_{i=1}^{I} \mu_{i}\left(u_{i}\left(c_{i, 2}\right)+\delta_{i, 1} u_{i}\left(c_{i, 3}\right)\right): \sum_{i=1}^{I}\left(c_{i, 2}, c_{i, 3}\right) \leq\left(e_{2}, e_{3}\right)\right\}
$$

for some vector of Pareto weights $\mu$. Using (2)-(3) together with the fact that there is a one-to-one relationship between efficient allocations and vectors of Pareto weights, it is not difficult to check that the only circumstance in which this will be the case is whenever the ratio $\delta_{i, 2} / \delta_{i, 1}^{2}$ is constant across consumers. This is automatically satisfied if consumers have time-consistent preferences. More generally, this ratio can be seen as a measure of the consumers' time-inconsistency. Thus date-1 Pareto efficient allocations are renegotiation-proof if and only if all consumers exhibit the same degree of inconsistency, that is when their discount factors are given by $\beta \delta_{i}$ and $\beta \delta_{i}^{2}$, for some common time-inconsistency parameter $\beta$. In multi-period economies, this generalizes to the requirement that the discount factors of a type- $i$ consumer are given by $\beta_{1} \delta_{i}, \beta_{2} \delta_{i}^{2}, \beta_{3} \delta_{i}^{2}, \ldots$, for all $i$.

\section{Two Economies with a Sequence of Markets}

The Second Welfare Theorem implies that date- 1 efficient allocations can be implemented using competitive markets in which trade in one- and two-period bonds takes place only at date 1 . When preferences are time-consistent, one can use this to construct an equivalent equilibrium for an economy with a sequence of markets in which

\footnotetext{
${ }^{6}$ An axiomatic foundation of such preferences can proceed mostly along the usual lines. To allow for time-inconsistency and still obtain subjective probabilities that satisfy Bayes' rule, one has to assume that preferences are consistent across information sets.
} 
consumers can trade one-period bonds (Arrow (1964)). A consumption plan that is feasible in one economy is feasible in the other, and time-consistency ensures that consumers who make plans at one date will not want to revise them at a later date. This last observation fails when preferences are time-inconsistent, and we therefore need to study economies with a sequence of markets separately.

\subsection{Markets}

We consider two market structures: one with markets for one-period discount bonds at dates 1 and 2, and another in which date- 1 consumers can also trade in lotteries that pay off in terms of date- 2 consumption. Date- 1 consumers may have an incentive to use these lotteries because time-inconsistency can introduce a non-convexity in their preferences over date- 2 wealth.

Consumers face no constraints on borrowing, other than that they must be able to pay off their debts at date 3. The sequence of bond markets allows consumers to exchange consumption at any one date for consumption at any other date. The price of date- $t$ consumption in terms of some numeraire is denoted by $p_{t}$ and we write $p=\left(p_{1}, p_{2}, p_{3}\right)^{\prime}$. Of course, the price in terms of date- $t$ consumption of a bond that pays one unit of consumption at date $t+1$ is simply $p_{t+1} / p_{t}$. We normalize prices so that $p \in \Delta_{3}$, the unit simplex of $\mathbb{R}_{++}^{3}$.

As in Pollak (1968), we view the same consumer at different dates as different decision makers. Taking prices as given, the date- $1,-2$, and date- 3 incarnations of a given consumer play a game. A trading strategy for the date- $t$ incarnation of a consumer is a decision how much to consume and save, and - if there are lottery markets - what lottery to buy over next-period wealth, given any history. We require these trading strategies to form a subgame perfect equilibrium of the intrapersonal game played between the three incarnations of the same consumer.

\subsection{The Date-2 Exchange Economy}

At date 3 , a consumer simply consumes his or her wealth, which consists of endowments and maturing bonds. At date 2, this same consumer must choose how much to consume and how many bonds to buy. Given non-negative wealth $w_{2}$ and prices $p \in \Delta_{3}$, a date- 2 consumer of type $i$ solves:

$$
\max _{\left(c_{2}, c_{3}\right) \in \mathbb{R}_{+}^{2}}\left\{u_{i}\left(c_{2}\right)+\delta_{1} u_{i}\left(c_{3}\right)\right\}
$$

subject to the budget constraint:

$$
p_{2} c_{2}+p_{3} c_{3} \leq p_{2} w_{2} .
$$

Let $c_{i, 2}\left(p, w_{2}\right)$ and $c_{i, 3}\left(p, w_{2}\right)$ be the decision rules that solve (4) for various prices $p$ and wealth levels $w_{2}$. The utility perceived by the date- 1 consumer from these choices is captured by a value function $V_{i}$ defined by:

$$
V_{i}\left(p, w_{2}\right)=\delta_{1} u_{i}\left(c_{i, 2}\left(p, w_{2}\right)\right)+\delta_{2} u_{i}\left(c_{i, 3}\left(p, w_{2}\right)\right) .
$$


For given prices $p$, there is no guarantee that this value function will be concave in date- 2 wealth $w_{2}$ if preferences are not time-consistent. This may give a date- 1 consumer an incentive to use lotteries. In the absence of lottery markets, the nonconcavity of $V_{i}(p, \cdot)$ can cause the set of optimal consumption and savings choices of a date-1 consumer to be non-convex.

\subsection{Bond Markets Only}

Consider first the case where no lottery markets exist for date- 2 wealth. By trading in one-period bonds, a date- 1 consumer of type $i$ with wealth $w_{1}$ can choose levels of date-1 consumption and date- 2 wealth that solve:

$$
\max _{\left(c_{1}, w_{2}\right) \in \mathbb{R}_{+}^{2}}\left\{u_{i}\left(c_{1}\right)+V_{i}\left(p, w_{2}\right)\right\}
$$

subject to the budget constraint:

$$
p_{1} c_{1}+p_{2} w_{2} \leq p_{1} w_{1}
$$

The set of solutions to this decision problem is denoted by $\left[c_{i, 1}, w_{i, 2}\right]\left(p, w_{1}\right)$. For any price vector $p \in \Delta_{3}$, let $w_{i, 1}(p)$ denote date-1 wealth of a consumer of type $i$ :

$$
w_{i, 1}(p)=\frac{1}{p_{1}} \sum_{t=1}^{3} p_{t} e_{i, t} .
$$

Given prices $p$ and date- 1 choices $\left(c_{1}, w_{2}\right)$, the consumption allocation of a consumer of type $i$ is given by:

$$
d_{i}\left(p, c_{1}, w_{2}\right)=\left[\begin{array}{c}
c_{1} \\
c_{i, 2}\left(p, w_{2}\right) \\
c_{i, 3}\left(p, w_{2}\right)
\end{array}\right] .
$$

By combining the solution to (6)-(7) with (8) and (9) one can construct the demand correspondence of a consumer of type $i$ :

$$
D_{i}(p)=d_{i}\left(p,\left[c_{i, 1}, w_{i, 2}\right]\left(p, w_{i, 1}(p)\right)\right) .
$$

Note that the consumption vector selected from $D_{i}(p)$ is determined by the point in $\left[c_{i, 1}, w_{i, 2}\right]\left(p, w_{i, 1}(p)\right)$ chosen by the date- 1 incarnation of a consumer of type $i$. Thus a date- 1 consumer of type $i$ will be indifferent between all points in $D_{i}(p)$. This implies that the average demand of consumers of type $i$ is given by the convex hull co $\left[D_{i}(p)\right]$. A non-extreme point of co $\left[D_{i}(p)\right]$ is obtained by having appropriate fractions of the consumers of type $i$ choose each of the points in $D_{i}(p)$.

The Boundary Behavior of Demand The proof of the existence of a competitive equilibrium that we construct below makes use of the following boundary property 
of $D_{i}(p)$ : if $p$ approaches the boundary of $\Delta_{3}$, then the demand for at least one of the goods grows without bound. If preferences are time consistent, then $D_{i}(p)$ is the outcome of a decision problem. The desired boundary property of demand is then a standard implication of strict monotonicity of preferences and the assumption that endowments are strictly positive (see Debreu (1982, Lemma 4)). We need to extend Debreu's lemma to the outcomes of intrapersonal games.

Lemma 1 Let $\left\{p_{n}\right\}$ be a sequence of price vectors in $\Delta_{3}$ that converges to some price vector at the boundary of $\Delta_{3}$. Then the sequence $\left\{\inf _{z \in D_{i}\left(p_{n}\right)}\|z\|\right\}$ goes to $+\infty$.

The proof for the cases in which the price of date- 1 consumption goes to zero is a direct consequence of Debreu's lemma. The proof for the cases in which the price of date- 1 consumption remains bounded away from zero relies on first-order necessary conditions for the decision problems of the date- 1 and date- 2 consumers. ${ }^{7}$ The firstorder conditions for the date- 2 consumer include:

$$
\begin{aligned}
\mathrm{D}_{-} u_{i}\left(c_{i, 2}\left(p, w_{2}\right)\right) / p_{2} & \geq \delta_{1} \mathrm{D}_{+} u_{i}\left(c_{i, 3}\left(p, w_{2}\right)\right) / p_{3} \\
\delta_{1} \mathrm{D}_{-} u_{i}\left(c_{i, 3}\left(p, w_{2}\right)\right) / p_{3} & \geq \mathrm{D}_{+} u_{i}\left(c_{i, 2}\left(p, w_{2}\right)\right) / p_{2}
\end{aligned}
$$

as long as $c_{i, 2}\left(p, w_{2}\right)>0$ and $c_{i, 3}\left(p, w_{2}\right)>0$, respectively. The fact that the date- 2 consumer could choose to spend any incremental wealth only on date- 2 consumption or only on date-3 consumption implies the following envelope condition:

$$
\mathrm{D}_{w+} F_{i}\left(p, w_{2}\right) / p_{2} \geq \max \left\{\mathrm{D}_{+} u_{i}\left(c_{i, 2}\left(p, w_{2}\right)\right) / p_{2}, \delta_{1} \mathrm{D}_{+} u_{i}\left(c_{i, 3}\left(p, w_{2}\right)\right) / p_{3}\right\},
$$

where $F_{i}\left(p, w_{2}\right)$ is the value function for a date- 2 consumer of type $i$. The date1 consumer does not have a convex decision problem, and $\left[c_{i, 1}, w_{i, 2}\right]$ is generally a correspondence. Nevertheless, for any $\left(c_{1}, w_{2}\right) \in\left[c_{i, 1}, w_{i, 2}\right]\left(p, w_{i, 1}(p)\right)$ it must be that:

$$
\text { D_ } u_{i}\left(c_{1}\right) / p_{1} \geq \mathrm{D}_{w+} V_{i}\left(p, w_{2}\right) / p_{2}
$$

as long as $c_{1}>0$. Otherwise, the date- 1 consumer could certainly improve utility by reducing date- 1 consumption by a small amount. Bounds on the marginal rates of substitution between date- 1 consumption and date- 2 or date- 3 consumption can be constructed from (13)-(14) if we can relate $\mathrm{D}_{w}^{+} F_{i}$ and $\mathrm{D}_{w}^{+} V_{i}$. Observe that:

$$
\begin{aligned}
V_{i}\left(p, w_{2}\right) & =\delta_{1}\left(F_{i}\left(p, w_{2}\right)+\left(\frac{\delta_{2}}{\delta_{1}^{2}}-1\right) \delta_{1} u_{i}\left(c_{i, 3}\left(p, w_{2}\right)\right)\right) \\
& =\frac{\delta_{2}}{\delta_{1}}\left(F_{i}\left(p, w_{2}\right)+\left(\frac{\delta_{1}^{2}}{\delta_{2}}-1\right) u_{i}\left(c_{i, 2}\left(p, w_{2}\right)\right)\right) .
\end{aligned}
$$

${ }^{7}$ The concavity of $u_{i}$ implies the existence of left and right derivatives, $D_{-} u_{i}$ and $D_{+} u_{i}$. For any function $f$ defined on $\Delta_{3} \times \mathbb{R}_{+}$with values in $\mathbb{R} \cup\{-\infty\}$ and finite except possibly at $(p, 0)$, let $\mathrm{D}_{w+} f(p, w)=\lim \sup _{\varepsilon \downarrow 0}(f(p, w+\varepsilon)-f(p, w)) / \varepsilon$. 
One implication of the additive separability of preferences and the concavity of $u_{i}$ is that date- 2 consumption and date- 3 consumption are normal goods for the date- 2 consumer. Therefore:

$$
\mathrm{D}_{w+} V_{i}\left(p, w_{2}\right) \geq \beta \mathrm{D}_{w+} F_{i}\left(p, w_{2}\right),
$$

where $\beta$ is either $\delta_{1}$ or $\delta_{2} / \delta_{1}$, depending on whether $\delta_{2} / \delta_{1}^{2}$ is larger or smaller than one. The first-order conditions (11)-(12) and (14) and the envelope condition (13) together with the bound (16) imply that for $t=2$ and $t=3 \inf _{z_{t} \in D_{i, t}(p)}\left|z_{t}\right|$ goes to infinity if $p_{t}$ goes to zero. For example, if $p_{2}$ goes to zero while $p_{1}$ and $p_{3}$ remain bounded away from zero, then $\mathrm{D}_{+} u_{i}\left(c_{i, 2}\left(p, w_{2}\right)\right) / p_{2}$ would go to infinity if $c_{i, 2}\left(p, w_{2}\right)$ did not grow without bound. It follows from (12) that date-3 consumption must go to zero, and from (13)-(16) that date-1 consumption must go to zero. But then the total value of consumer $i$ 's consumption would go to zero. This contradicts the fact that $p_{1} w_{i, 1}(p)$ remains bounded away from zero. Similar contradictions can be derived from (11)-(16) if $p_{3}$ goes to zero or if $p_{2}$ and $p_{3}$ both go to zero.

Existence of a Competitive Equilibrium A competitive equilibrium is given by prices $p \in \Delta_{3}$ such that zero is an element of the value at $p$ of the aggregate excess demand correspondence implied by (10):

$$
0 \in \sum_{i=1}^{I}\left(\operatorname{co}\left[D_{i}(p)\right]-e_{i}\right) .
$$

Under our assumptions on the utility functions $u_{i}$, the decision problem of a date- 2 consumer is completely standard. The decision rules $c_{i, 2}$ and $c_{i, 3}$ are continuous on $\Delta_{3} \times \mathbb{R}_{+}$, which implies that $d_{i}$ as given by (9) is continuous on $\Delta_{3} \times \mathbb{R}_{++}^{2}$, and it is not difficult to see that for every $p \in \Delta_{3}, V_{i}(p, \cdot)$ is also continuous on $\mathbb{R}_{++}$. Furthermore, $V_{i}(p, \cdot)$ exhibits the same behavior at zero as $u_{i}$.

The demand correspondence $D_{i}$ is constructed using the composition of the continuous function $d_{i}$ with $\left[c_{i, 1}, w_{i, 2}\right]$ and the continuous function $w_{i, 1}$ in (8). The Maximum Theorem implies that $\left[c_{i, 1}, w_{i, 2}\right]$ is a non-empty, upper-hemicontinuous and compactvalued correspondence on $\Delta_{3} \times \mathbb{R}_{++}$. It follows that $D_{i}$ is upper-hemicontinuous on $\Delta_{3}$, with non-empty and compact values (Aliprantis and Border (1999, Theorem $16.23)$ ). But then $\operatorname{co}\left[D_{i}\right]$ is also upper-hemicontinuous on $\Delta_{3}$, with non-empty convex and compact values (Aliprantis and Border (1999, Theorem 16.35)).

The excess demand correspondence obtained by aggregating across types will again be upper-hemicontinuous and convex-valued. As usual, it is bounded below by the aggregate endowments and satisfies Walras' Law. The excess demand correspondence inherits the boundary property of $D_{i}(p)$ shown in Lemma 1 . One can now apply a theorem of Debreu (1982, Theorem 8) to establish the following result.

Proposition 2 There exists a competitive equilibrium. 
This proposition continues to apply if consumers of different types have different subjective discount factors.

The Incentive to Gamble Suppose $p$ is a vector of equilibrium prices at which date- 1 consumers of type $i$ are indifferent between two distinct pairs $\left(c_{1}, w_{2}\right)$ and $\left(c_{1}^{\prime}, w_{2}^{\prime}\right)$. Suppose that a fraction $\theta \in(0,1)$ chooses $\left(c_{1}, w_{2}\right)$ while the remainder chooses $\left(c_{1}^{\prime}, w_{2}^{\prime}\right)$. Now imagine that after trading in bonds, consumers of type $i$ could get together at date-1 and re-allocate their collective resources. One possible reallocation would give each of them $\theta c_{1}+(1-\theta) c_{1}^{\prime}$ to consume at date 1 , together with a lottery that delivers $w_{2}$ units of date- 2 wealth with probability $\theta$ and $w_{2}^{\prime}$ with probability $1-\theta$. The expected date- 1 utility of consumers of type $i$ under this alternative allocation will be strictly greater than under the equilibrium allocation:

$$
\begin{aligned}
& u_{i}\left(\theta c_{1}+(1-\theta) c_{1}^{\prime}\right)+\theta V_{i}\left(p, w_{2}\right)+(1-\theta) V_{i}\left(p, w_{2}^{\prime}\right)> \\
& \theta\left[u_{i}\left(c_{1}\right)+V_{i}\left(p, w_{2}\right)\right]+(1-\theta)\left[u_{i}\left(c_{1}^{\prime}\right)+V_{i}\left(p, w_{2}^{\prime}\right)\right]=u_{i}\left(c_{1}\right)+V_{i}\left(p, w_{2}\right),
\end{aligned}
$$

by the strict concavity of $u_{i}$ and the indifference between $\left(c_{1}, w_{2}\right)$ and $\left(c_{1}^{\prime}, w_{2}^{\prime}\right)$. In fact, the date- 1 consumers of type $i$ can do even better by choosing a lottery that maximizes their expected utility of date- 2 wealth.

It is not difficult to see that if the date- 1 consumers of type $i$ can re-allocate their resources in this way, they have an incentive to engage in further bond trades at the supposed equilibrium prices $p$. This suggests that an equilibrium in which different consumers of the same type make different choices may not be very stable.

There is a further reason why such an equilibrium might not be stable. Although the date- 1 consumers of some type may in equilibrium be indifferent between two choices, the date-2 incarnations of these same consumers will typically not be indifferent. Suppose now that date-1 consumers make their choices lexicographically: maximize date- 1 utility, and when indifferent select a choice that maximizes date- 2 utility. All date-1 consumers of one type will then typically want to make the same choice, and this would break the proposed equilibrium.

\subsection{Bonds and Lotteries}

Consumers at date 1 can now also trade in lotteries with payoffs in terms of date2 consumption. A lottery with distribution $\mu$ trades at the actuarially fair price of $\left(p_{2} / p_{1}\right) \int c \mathrm{~d} \mu(c)$ units of date- 1 consumption. A date- 1 consumer of type $i$ with wealth $w_{1}$ then chooses date- 1 consumption and a lottery over date- 2 wealth to solve: ${ }^{8}$

$$
\max _{c_{1} \in \mathbb{R}_{+}, \mu \in \Delta\left(\mathbb{R}_{+}\right)}\left\{u_{i}\left(c_{1}\right)+\int V_{i}\left(p, w_{2}\right) \mathrm{d} \mu\left(w_{2}\right)\right\}
$$

subject to the budget constraint:

$$
p_{1} c_{1}+p_{2} \int w_{2} \mathrm{~d} \mu\left(w_{2}\right) \leq p_{1} w_{1}
$$

${ }^{8}$ The set of Borel probability measures over a complete metric space $X$ is denoted by $\Delta(X)$, and is endowed with the usual topology of weak convergence. 
Because of the possible non-concavity of $V_{i}(p, \cdot)$, there may be multiple solutions to this decision problem. Note however that the strict concavity of $u_{i}$ does imply that for every $\left(p, w_{1}\right) \in \Delta_{3} \times \mathbb{R}_{++}$there can be at most one optimal level of date-1 consumption. We denote this by $c_{i, 1}\left(p, w_{1}\right)$ and write $\mu_{i}\left(\cdot \mid p, w_{1}\right)$ for the set of lotteries that solve (18)-(19).

For any price vector $p \in \Delta_{3}$, date- 1 wealth of a consumer of type $i$ is again given by (8). The expected consumption choices of a consumer of type $i$ are therefore:

$$
\bar{c}_{i, 1}(p)=c_{i, 1}\left(p, w_{i, 1}(p)\right)
$$

at date 1, and:

$$
\left[\begin{array}{l}
\bar{c}_{i, 2}(p) \\
\bar{c}_{i, 3}(p)
\end{array}\right]=\int\left[\begin{array}{c}
c_{i, 2}\left(p, w_{2}\right) \\
c_{i, 3}\left(p, w_{2}\right)
\end{array}\right] \mathrm{d} \mu_{i}\left(w_{2} \mid p, w_{i, 1}(p)\right)
$$

at dates 2 and 3. (The right-hand side of (21) is interpreted as the set of values in $\mathbb{R}_{+}^{2}$ obtained by integrating against all of the probability distributions in $\mu_{i}\left(\cdot \mid p, w_{i, 1}(p)\right)$.)

The Date-1 Decision Problem To show that a symmetric lottery equilibrium always exists, we must impose a boundary condition on preferences that was not needed to establish the existence of possibly asymmetric no-lottery equilibria.

Assumption $\mathbf{U}$ The utility functions $u_{i}$ are such that either $u_{i}$ is bounded below and $\lim _{c \rightarrow \infty} u_{i}(c) / c=0$, or $c \mathrm{D}_{+} u_{i}(c)$ remains bounded as $c$ goes to $+\infty$.

The condition that $u_{i}(c) / c$ goes to zero as $c$ increases without bound implies that consumers are not approximately risk neutral at high levels of consumption. ${ }^{9}$ The value function $V_{i}$ inherits this property of $u_{i}$ : as $w$ gets large, $V_{i}(p, w) / w$ goes to zero.

A difficulty in characterizing the solution to the decision problem of a date-1 consumer is the fact that the set of lotteries available to a date- 1 consumer is not compact. In particular, a date- 1 consumer could use a lottery that assigns a positive probability to arbitrarily high levels of date- 2 wealth. The fact that $V_{i}(p, w) / w$ goes to zero as $w$ gets large ensures that this will never be optimal. This implies that one can restrict attention to lotteries with a support contained in some compact subset of $\mathbb{R}_{+}$. The boundary condition at zero ensures that one can take the support of an optimal lottery to be a compact subset of $\mathbb{R}_{+}$on which $V_{i}(p, \cdot)$ is continuous. To prove that the choices of a date- 1 consumer vary continuously with prices, we need this last observation to hold in some sense uniformly in $\left(p, w_{1}\right)$. The following lemma asserts that this is indeed the case. The proof is given in the Appendix.

Lemma 2 Suppose Assumption U holds, and consider any compact $P$ in $\Delta_{3}$ and $W_{i, 1}$ in $\mathbb{R}_{++}$. Then there are compact subsets $C_{i}$ and $W_{i, 2}$ of $\mathbb{R}_{+}$(of $\mathbb{R}_{++}$if $u_{i}$

\footnotetext{
${ }^{9}$ This is the assumption used by Kehoe, Levine and Prescott (2001) in the context of a private information economy with lottery markets.
} 
is not bounded below) such that any solution to the date-1 problem (18)-(19) is in $C_{i} \times \Delta\left(W_{i, 2}\right)$ for every $\left(p, w_{1}\right)$ in $P \times W_{i, 1}$.

Lotteries Versus Deterministic Allocations A minimal requirement for a date-1 consumer of type $i$ to prefer a lottery $\mu$ over saving a deterministic amount $\bar{w}(\mu)=$ $\int w \mathrm{~d} \mu(w)$ is:

$$
V_{i}(p, \bar{w}(\mu)) \leq \delta_{1} u_{i}\left(\bar{c}_{i, 2}(p, \mu)\right)+\delta_{2} u_{i}\left(\bar{c}_{i, 3}(p, \mu)\right)
$$

where $\bar{c}_{i, t}(p, \mu)$ represents the mean of $c_{i, t}(p, w)$ when $w$ is generated by a lottery $\mu$. At the very least, the date- 1 continuation utility of expected consumption under the lottery must exceed the date- 1 continuation utility of the consumption choices induced by saving $\bar{w}(\mu)$. Otherwise the uncertainty of the lottery can only make the date- 1 consumer worse off.

To gain some further insight in the properties of optimal lotteries, consider the case of present bias $\left(\delta_{2} / \delta_{1}^{2}>1\right.$.) Using the first part of (15) and the fact that $F_{i}$ is concave in wealth, one can verify that:

$$
\int V_{i}(p, w) \mathrm{d} \mu(w) \leq V_{i}(p, \bar{w}(\mu))+\left(\frac{\delta_{2}}{\delta_{1}^{2}}-1\right) \delta_{1}^{2}\left[u_{i}\left(\bar{c}_{i, 3}(p, \mu)\right)-u_{i}\left(c_{i, 3}(p, \bar{w}(\mu))\right)\right]
$$

If the date- 1 consumer weakly prefers a lottery $\mu$ to saving $\bar{w}(\mu)$, then the second term in this expression must be non-negative. In these circumstances, therefore, $c_{i, 2}(p, \bar{w}(\mu)) \geq \bar{c}_{i, 2}(p, \mu)$ and $c_{i, 3}(p, \bar{w}(\mu)) \leq \bar{c}_{i, 3}(p, \mu)$. In the case of future bias, one can use the second part of (15) to verify that both these inequalities are reversed.

The only reason the date- 1 consumer might want to use a lottery is to counter the biases generated by the preferences of the date- 2 consumer. In the case of present bias, the date- 2 consumer consumes "too much" at date 2 , and an actuarially fair lottery can only be advantageous if expected date- 2 consumption is lower than it would be if the date- 1 consumer chose to save the same amount deterministically.

The date-2 budget constraint implies that $p_{3}\left[\bar{c}_{i, 3}(p, \mu)-c_{i, 3}(p, \bar{w}(\mu))\right]$ is equal to $p_{2}\left[c_{i, 2}(p, \bar{w}(\mu))-\bar{c}_{i, 2}(p, \mu)\right]$. In the case of present bias, both these quantities are positive if $\mu$ is strictly preferred to $\bar{w}(\mu)$. We can therefore also write $(22)$ as:

$$
\frac{\delta_{2}\left[u_{i}\left(\bar{c}_{i, 3}(p, \mu)\right)-u_{i}\left(c_{i, 3}(p, \bar{w}(\mu))\right)\right]}{p_{3}\left[\bar{c}_{i, 3}(p, \mu)-c_{i, 3}(p, \bar{w}(\mu))\right]} \geq \frac{\delta_{1}\left[u_{i}\left(c_{i, 2}(p, \bar{w}(\mu))\right)-u_{i}\left(\bar{c}_{i, 2}(p, \mu)\right)\right]}{p_{2}\left[c_{i, 2}(p, \bar{w}(\mu))-\bar{c}_{i, 2}(p, \mu)\right]}
$$

whenever the lottery $\mu$ is strictly preferred to saving $\bar{w}(\mu)$ deterministically. The reverse holds in the case of future bias. We shall use (23) below to study the properties of expected consumption as relative prices go to zero.

The Boundary Behavior of Demand If $\bar{c}_{i, 1}(p)$ is positive, then it must be that the date- 1 consumer could not have done better by reducing date- 1 consumption by some small positive $\varepsilon / p_{1}$. One possible use of the resulting increment in savings would have been to shift the distribution $\mu_{i}\left(\cdot \mid p, w_{i, 1}(p)\right)$ to the right by $\varepsilon / p_{2}$. Together with 
(15), the normality of date-2 and date-3 consumption, and the envelope condition (13) for the date-2 problem, this implies that:

$$
\frac{\mathrm{D}_{-} u_{i}\left(\bar{c}_{i, 1}(p)\right)}{p_{1}} \geq \beta \int \frac{\mathrm{D}_{+} u_{i}\left(c_{i, 2}(p, w)\right)}{p_{2}} \mathrm{~d} \mu_{i}\left(w \mid p, w_{i, 1}(p)\right)
$$

as long as $\bar{c}_{i, 1}(p)$ is positive. As in (16), $\beta$ is either $\delta_{1}$ or $\delta_{2} / \delta_{1}$, depending on whether $\delta_{2} / \delta_{1}^{2}$ is larger or smaller than one. Define:

$$
\bar{w}_{i, 2}(p)=\int w \mathrm{~d} \mu_{i}\left(w \mid p, w_{i, 1}(p)\right)
$$

and consider what happens if $p_{2}$ goes to zero and $p_{1}$ and $p_{3}$ remain bounded away from zero.

Suppose that $\bar{c}_{i, 2}(p)$ remains bounded. This implies that $\mu_{i}\left(\cdot \mid p, w_{i, 1}(p)\right)$ must assign probabilities that remain bounded away from zero to some interval of wealth on which $c_{i, 2}(p, w)$ is bounded. The right-hand side of (24) must therefore grow without bound as $p_{2}$ gets small. This yields an immediate contradiction if marginal utility at zero is bounded. Alternatively, it implies that date- 1 consumption must go to zero. In that case, $p_{2} \bar{w}_{i, 2}(p)$ also remains bounded away from zero. It then follows from the first-order conditions of the date- 2 problem that $c_{i, 2}\left(p, \bar{w}_{i, 2}(p)\right)$ must grow without bound. If preferences exhibit future bias, this yields an immediate contradiction, since $\bar{c}_{i, 2}(p) \geq c_{i, 2}\left(p, \bar{w}_{i, 2}(p)\right)$. It remains to consider the case of present bias. There are three subcases to distinguish.

Suppose first that $u_{i}$ is bounded below but not above. Since $c_{i, 2}\left(p, \bar{w}_{i, 2}(p)\right)$ grows without bound it follows that $V_{i}\left(p, \bar{w}_{i, 2}(p)\right)$ grows without bound. At the same time, $\bar{c}_{i, 2}(p)$ and $\bar{c}_{i, 3}(p)$ are supposed to remain bounded. This implies a violation of $(22)$ for any optimal lottery.

Next, suppose that $u_{i}$ is bounded above. This implies that $c \mathrm{D}_{+} u_{i}(c)$ goes to zero as $c$ gets large. The first-order conditions (11)-(12) of the date-2 decision problem then imply that $p_{2} c_{i, 2}\left(p, \bar{w}_{i, 2}(p)\right)$ must go to zero, and that $c_{i, 3}\left(p, \bar{w}_{i, 2}(p)\right)$ remains bounded away from zero. Since $c_{i, 2}\left(p, \bar{w}_{i, 2}(p)\right)$ grows without bound and $\bar{c}_{i, 2}(p)$ is supposed to remain bounded, this will eventually violate (23) for any optimal lottery.

Finally, suppose that $u_{i}$ is unbounded below and that $c \mathrm{D}_{+} u_{i}(c)$ remains bounded as $c$ gets large. If the date- 1 consumer chooses deterministic date- 2 wealth levels $w_{2}$ so that $p_{2} w_{2}$ remains bounded away from zero, then the first-order conditions (11)-(12) of the date- 2 problem imply that $c_{i, 2}\left(p, w_{2}\right)$ grows without bound and that $c_{i, 3}\left(p, w_{2}\right)$ remains bounded away from zero. Since $p_{1} w_{i, 1}(p)$ remains bounded away from zero, this means that the date- 1 consumer can guarantee a level of utility that is bounded below at all prices. On the other hand, the fact that date- 1 consumption $\bar{c}_{i, 1}(p)$ must go to zero if $\bar{c}_{i, 2}(p)$ remains bounded implies that choosing a lottery for which average date- 2 consumption remains bounded generates utility that shrinks down to $-\infty$. This cannot be optimal. 
Using similar lines of reasoning for other relative prices that go to zero, one can establish the following lemma.

Lemma 3 Suppose that Assumption U holds, and let $\left\{p_{n}\right\}$ be a sequence of price vectors in $\Delta_{3}$ that converges to some price vector at the boundary of $\Delta_{3}$. Then the sequence $\left\{\inf _{z \in \bar{c}_{i}\left(p_{n}\right)}\|z\|\right\}$ goes to $+\infty$.

Existence of a Competitive Equilibrium We focus on showing the existence of symmetric equilibria in which all consumers of a given type make the same choices. This means that the aggregate demand correspondence is given by the sum over types $i$ of (20)-(21). A competitive equilibrium is given by prices $p \in \Delta_{3}$ such that zero is an element of the value at $p$ of the aggregate excess demand correspondence implied by $(20)-(21)$ :

$$
0 \in \sum_{i=1}^{I}\left(\bar{c}_{i}(p)-e_{i}\right) .
$$

Consider any $P \times W_{i, 1}$ and associated $C_{i}$ and $W_{i, 2}$ as in Lemma 2. We can restrict the choices of a date- 1 consumer of type $i$ to $C_{i} \times \Delta\left(W_{i, 2}\right)$. Subject to this restriction, the correspondence that assigns budget-feasible consumption choices and lotteries to elements of $P \times W_{i, 1}$ is then non-empty, compact-valued and continuous. It follows from the Maximum Theorem that $\left(c_{i, 1}, \mu_{i}\right)$ is an upper-hemicontinuous correspondence on $P \times W_{i, 1}$ with non-empty and compact values. Clearly, $w_{i, 1}$ as defined in (8) is continuous on $P$. Thus $\bar{c}_{i, 1}$ as given by $(20)$ is continuous on $P$. Expected demand for date-2 and date- 3 consumption $\left(\bar{c}_{i, 2}, \bar{c}_{i, 3}\right)$ is defined as the composition of the function $\mu \mapsto \int\left[c_{i, 2}\left(p, w_{2}\right), c_{i, 3}\left(p, w_{2}\right)\right]^{\prime} \mathrm{d} \mu\left(w_{2}\right)$, which is continuous on $\Delta\left(W_{i, 2}\right)$ since the decision rules $c_{i, 2}$ and $c_{i, 3}$ are continuous on $P \times W_{i, 2}$, with the upperhemicontinuous correspondence $\left(p, w_{1}\right) \mapsto \mu_{i}\left(\cdot \mid p, w_{1}\right)$ and the continuous function $p \mapsto\left(p, w_{i, 1}(p)\right)$. It follows that $\left(\bar{c}_{i, 2}, \bar{c}_{i, 3}\right)$ must be an upper-hemicontinuous correspondence on $P$ (Aliprantis and Border (1999, Theorem 16.23)). Moreover, it is not difficult to see that this correspondence has non-empty convex and compact values. Using the boundary property of $\bar{c}_{i}$ shown in Lemma 3 , the proof of the following proposition now proceeds exactly as in the case of no-lottery equilibria.

Proposition 3 If consumers have utility functions that satisfy Assumption U, then there exists a competitive equilibrium.

Again, Proposition 3 continues to apply if consumers of different types have different subjective discount factors.

\subsection{A Lottery Example}

To verify that both asymmetric equilibria without lotteries and symmetric equilibria with lotteries can occur, consider an economy with only one type of consumer whose 
period utility function is:

$$
u(c)=\int_{0}^{c} \exp \left(-x^{2}\right) \mathrm{d} x .
$$

(We omit the type-subscripts in this section.) Note that $-c \mathrm{D}^{2} u(c) / \mathrm{D} u(c)=c^{2}$, and so the coefficient of relative risk aversion is close to zero for low levels of consumption. Suppose $\delta_{1}=.1, \delta_{2}=.9$ and $p_{3} / p_{2}=.05$. The value function $V(p, \cdot)$ and the convex hull of its epigraph are shown in Figure 1. For levels of date-2 wealth below $w_{*}$, the consumer chooses $c_{2}=0$. This generates a kink in the value function at $w_{*}$, something that would not be possible if preferences were time-consistent. Note that $V(p, \cdot)$ has the shape used by Friedman and Savage (1948) to interpret evidence suggesting that consumers at low levels of wealth buy insurance and gamble at the same time.

\section{Figure 1}

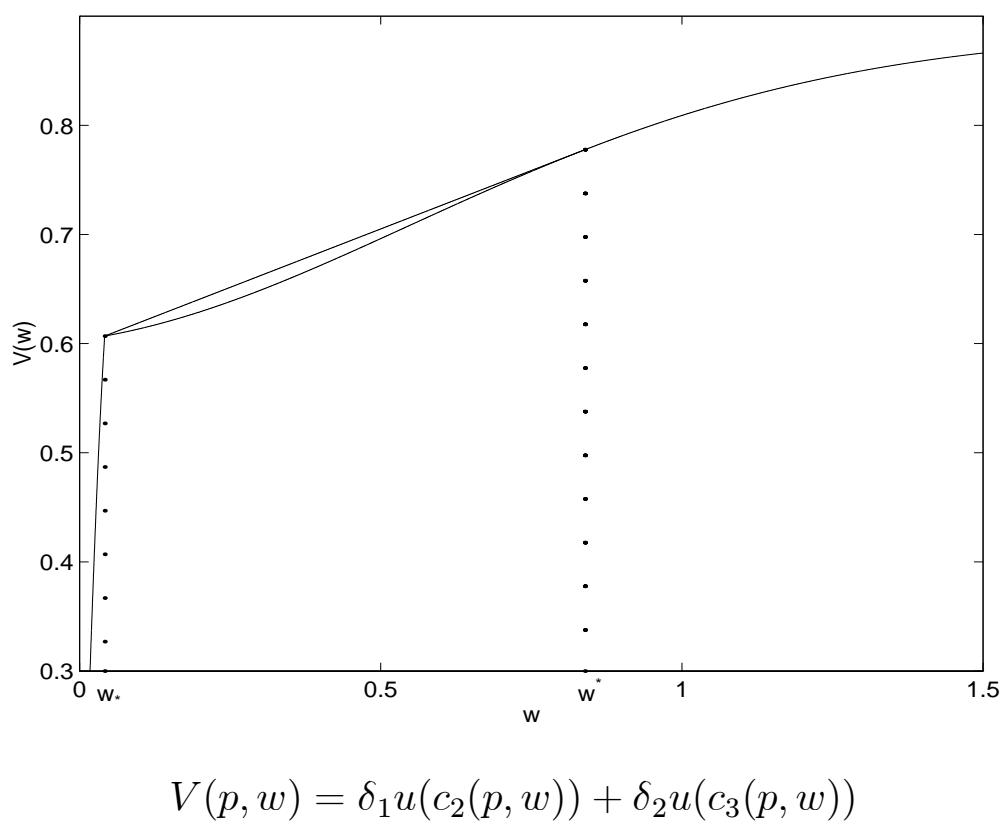

It is not difficult to construct an economy in which the value function shown in Figure 1 is part of the competitive equilibrium. Take some $\theta \in(0,1)$ and any $e_{1}>0$, and let $e_{t}=\theta c_{t}\left(p, w_{*}\right)+(1-\theta) c_{t}\left(p, w^{*}\right)$ for $t=2,3$. The price of a date- 1 discount bond is $p_{2} / p_{1}=\mathrm{D} V\left(p, w^{*}\right) / \exp \left(-e_{1}^{2}\right)$. In equilibrium, everyone consumes their endowments at date 1 and chooses to hold a lottery that pays $w_{*}-\left(p_{2} e_{2}+p_{3} e_{3}\right) / p_{2}$ with probability $\theta$ and $w^{*}-\left(p_{2} e_{2}+p_{3} e_{3}\right) / p_{2}$ with probability $1-\theta$. Given prices, these choices are optimal and markets clear by construction.

For certain endowments, there is no symmetric equilibrium in which no lotteries are used. The price of a discount bond at date 2 would have to be $p_{3} / p_{2}=$ $\delta_{1} \exp \left(-\left(e_{3}^{2}-e_{2}^{2}\right)\right)$ in such an equilibrium. But for $\theta=.5$ and endowments $e_{2}$ and $e_{3}$ constructed as above, $\left(p_{2} e_{2}+p_{3} e_{3}\right) / p_{2}$ turns out to be in the convex range of the 
value function $V(p, \cdot)$. The asymmetric no-lottery equilibrium for the same economy with $e_{1}=.15$ is shown in Figure 2 .

Figure 2

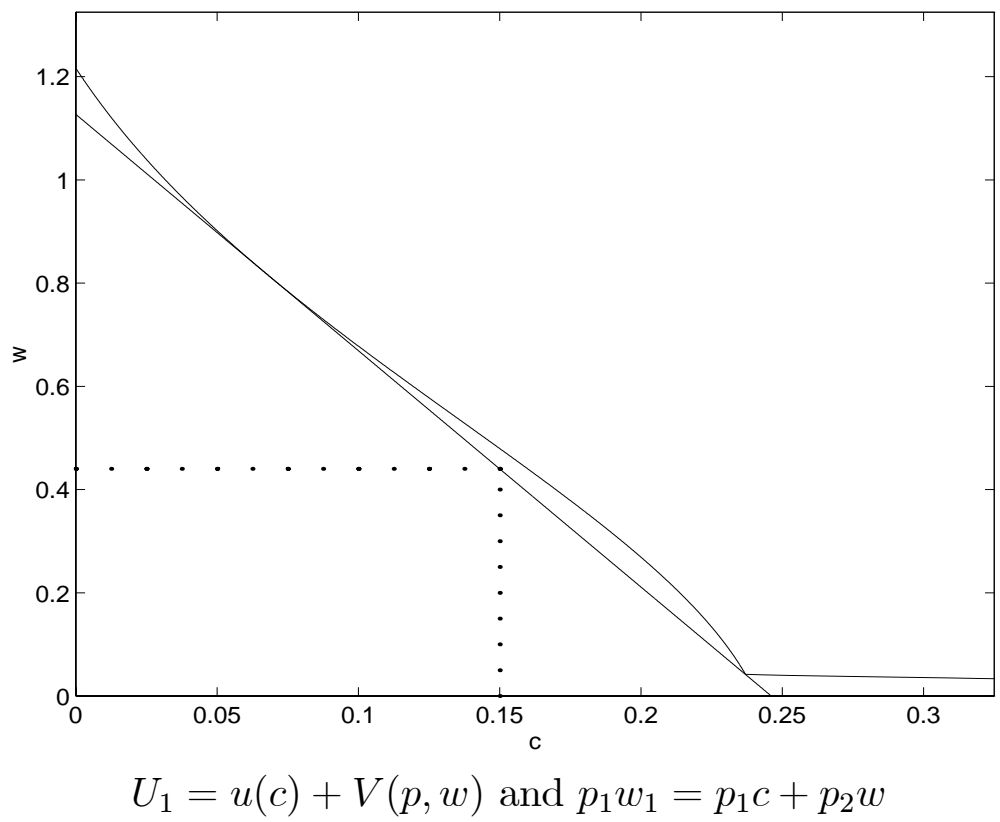

It turns out that date- 1 utility in the lottery equilibrium is slightly higher than date-1 utility in the no-lottery equilibrium. Thus the existence of lottery markets makes the date- 1 consumers better off. But the difference in date- 1 utilities is smaller than that suggested by (17). While date- 1 consumption is the same for all consumers in the lottery equilibrium, equilibrium prices are such that the dispersion of their date- 2 and date-3 consumption is larger than in the no-lottery equilibrium. It can be verified that for alternative parameters this can overturn the effect of (17) and reverse the utility comparison between the two equilibria. It is therefore not possible to conclude that either lottery equilibria or no-lottery equilibria will always be better in terms of date-1 preferences. Note however that asymmetric no-lottery equilibria are weakly Pareto efficient, while symmetric lottery equilibria are not.

\section{Smooth Preferences}

We want to know under what circumstances competitive equilibria are date-1 Pareto efficient. Clearly, this will not be the case for asymmetric equilibria, or when lotteries are used. In symmetric equilibria in which no lotteries are used, more can be said about the properties of a competitive equilibrium when we assume that the utility functions $u_{i}$ are sufficiently smooth.

Assumption $\mathbf{S}$ The utility functions $u_{i}$ have continuous derivatives up to any order on $\mathbb{R}_{++}$, and $\lim _{c \downarrow 0} \mathrm{D} u_{i}(c)=+\infty$. 


\subsection{Efficient Allocations}

Proposition 1 together with Assumption S implies that for a vector of aggregate endowments $e$, the set of interior date-1 Pareto efficient allocations is given by those $c$ that for some $\lambda \in \mathbb{R}_{++}^{I}$ and $p \in \mathbb{R}_{++}^{3}$ satisfy the marginal conditions:

$$
\lambda_{i} \mathrm{D} u_{i}\left(c_{i, t}\right)=p_{t}
$$

and feasibility conditions:

$$
\sum_{i=1}^{I} c_{i, t}=e_{t}
$$

for all $i$ and $t$. We can take $\lambda$ to be in the unit simplex $\Delta_{I}$ of $\mathbb{R}_{++}^{I}$. Let $\mathcal{P}$ be the set of pairs $(e, c)$ of aggregate endowments and consumption allocations that satisfy (25)-(26).

As defined in (25)-(26), $\mathcal{P}$ is parameterized by pairs $(e, \lambda)$ of aggregate endowments and Pareto weights. It will be more convenient below to parameterize $\mathcal{P}$ instead using the vector of aggregate endowments $e$, together with a feasible allocation $c_{t}$ at one particular date $t$. To construct such a parameterization, consider some $\left(e_{t}, \lambda\right)$ in $\mathbb{R}_{++} \times \Delta_{I}$ and solve the date- $t$ version of (25)-(26) for $\left(e_{t}, c_{t}\right)$. This defines a function $g$ that maps $\mathbb{R}_{++} \times \Delta_{I}$ into the set $F$ that consists of pairs $\left(e_{t}, c_{t}\right)$ that satisfy the feasibility constraint (26). The inverse of this function is given by $\left(e_{t}, l\left(c_{t}\right)\right)$, where:

$$
l_{i}\left(c_{t}\right)=\left(\sum_{j=1}^{I} \frac{1}{\mathrm{D} u_{j}\left(c_{j, t}\right)}\right)^{-1} \frac{1}{\mathrm{D} u_{i}\left(c_{i, t}\right)}
$$

for each $i$. The following lemma is proved in the Appendix.

Lemma 4 The function $g: \mathbb{R}_{++} \times \Delta_{I} \rightarrow F$ is a diffeomorphism.

Take a vector $\left(e, c_{t}\right)$ such that $\left(e_{t}, c_{t}\right) \in F$, and define:

$$
\left(e_{s}, c_{s}\right)=g\left(e_{s}, l\left(c_{t}\right)\right)
$$

for all $s=1,2,3$. This defines a map $\varphi_{t}$ that takes any $\left(e_{t}, c_{t}, e_{-t}\right)$ from $\Theta=F \times \mathbb{R}_{++}^{2}$ and maps it into $\mathcal{P}$. The fact that $g$ is a diffeomorphism implies that $\varphi_{t}: \Theta \rightarrow \mathcal{P}$ is a diffeomorphism as well. Clearly, $\Theta$ is a manifold of dimension $I+2$, and so $\mathcal{P}$ must be too. Given aggregate endowments, the manifold of Pareto efficient allocations is, as expected, of dimension $I-1$.

\subsection{Equilibrium Allocations}

Fix some price vector $p \in \mathbb{R}_{++}^{3}$. Under Assumption $\mathrm{S}$, the decisions of a date-2 consumer of type $i$ with positive wealth $w_{2}$ are fully characterized by the date- 2 budget constraint and the usual first-order condition:

$$
\frac{p_{3}}{p_{2}}=\frac{\delta_{1} \mathrm{D} u_{i}\left(c_{i, 3}\left(p, w_{2}\right)\right)}{\mathrm{D} u_{i}\left(c_{i, 2}\left(p, w_{2}\right)\right)} .
$$


Moreover, for a fixed $p$, the decision rules $c_{i, 2}(p, \cdot)$ and $c_{i, 3}(p, \cdot)$ are differentiable functions of wealth. Differentiating $(27)$ and the date-2 budget constraint with respect to $w_{2}$, one can verify that $\mathrm{D}_{w} V_{i}\left(p, w_{2}\right)$ must be given by:

$$
\mathrm{D}_{w} V_{i}\left(p, w_{2}\right)=f_{i}\left(c_{i, 2}\left(p, w_{2}\right), c_{i, 3}\left(p, w_{2}\right)\right) \mathrm{D} u_{i}\left(c_{i, 2}\left(p, w_{2}\right)\right)
$$

where the function $f_{i}$ is defined as:

$$
f_{i}(x, y)=\frac{\delta_{1} \frac{\left[\mathrm{D} u_{i}(x)\right]^{2}}{\mathrm{D}^{2} u_{i}(x)}+\delta_{2} \frac{\left[\mathrm{D} u_{i}(y)\right]^{2}}{\mathrm{D}^{2} u_{i}(y)}}{\frac{\left[\mathrm{D} u_{i}(x)\right]^{2}}{\mathrm{D}^{2} u_{i}(x)}+\delta_{1} \frac{\left[\mathrm{D} u_{i}(y)\right]^{2}}{\mathrm{D}^{2} u_{i}(y)}} .
$$

Note that in the case of time-consistent preferences, this expression reduces to $\delta_{1}$, as expected from (28) and the envelope condition of consumer $i$ 's date-2 maximization problem. If a date- 1 consumer of type $i$ with wealth $w_{1}$ chooses not to use lotteries, then his consumption and wealth choices must satisfy the date-1 budget constraint and the usual first-order condition:

$$
\frac{p_{2}}{p_{1}}=\frac{\mathrm{D}_{w} V_{i}\left(p, w_{2}\right)}{\mathrm{D} u_{i}\left(c_{i, 1}\left(p, w_{1}\right)\right)}
$$

Any feasible consumption allocation that satisfies (27)-(29) for all consumers $i$ and some prices $p$ is a candidate for an equilibrium allocation without lotteries. Such an allocation will be a competitive equilibrium for some distribution of endowments if no consumer can do better using an actuarially fair lottery.

A convenient way to describe the set of candidate equilibrium allocations is obtained by defining:

$$
m_{i}\left(c_{i}\right)=\left[\begin{array}{c}
\mathrm{D} u_{i}\left(c_{i, 1}\right) \\
f_{i}\left(c_{i, 2}, c_{i, 3}\right) \mathrm{D} u_{i}\left(c_{i, 2}\right) \\
f_{i}\left(c_{i, 2}, c_{i, 3}\right) \mathrm{D} u_{i}\left(c_{i, 3}\right)
\end{array}\right] .
$$

Given aggregate endowments $e$, a feasible allocation $c$ that is part of a competitive equilibrium without lotteries must for some $\lambda \in \Delta_{I}$ and $p \in \mathbb{R}_{++}^{3}$ satisfy:

$$
\lambda_{i} m_{i, t}\left(c_{i}\right)=p_{t}
$$

for all $i$ and $t$. Because first-order conditions need not be sufficient, some of the feasible allocations admitted by (30) may not correspond to an equilibrium. It turns out that competitive equilibria without lotteries have standard local uniqueness properties.

Proposition 4 Except for economies with endowments in a set of measure zero, symmetric competitive equilibria without lotteries are locally unique.

The collection of $(e, c)$ such that $c$ is a symmetric competitive equilibrium allocation given aggregate endowments $e$ is contained in a manifold of dimension $I+2$. 


\subsection{Efficient Equilibrium Allocations}

A comparison of (25) and (30) shows that competitive equilibria are efficient if and only if the $f_{i}\left(c_{i, 2}, c_{i, 3}\right)$ are the same across consumers. By adding this restriction to the conditions (25)-(26) for efficiency, we can determine which of the efficient allocations could potentially be decentralized as equilibrium allocations. From now on, we shall assume that preferences are time-inconsistent. Adding the restriction that the $f_{i}\left(c_{i, 2}, c_{i, 3}\right)$ coincide to the definition of an efficient allocation is therefore equivalent to adding the requirement that for some $\xi>0$ and all $i$ :

$$
\frac{\mathrm{D}^{2} u_{i}\left(c_{i, 3}\right)}{\mathrm{D}^{2} u_{i}\left(c_{i, 2}\right)}=\xi
$$

Relative to the definition of $\mathcal{P}$, this adds $I$ additional restrictions and the new variable $\xi$. Since $\mathcal{P}$ is an $(I+2)$-dimensional manifold, this suggests that the set of efficient equilibrium allocations is 3-dimensional. For given aggregate endowments, this would imply that there are only isolated points at which the equilibrium and efficient allocations coincide.

Whether or not this is indeed the case depends on whether the equations (31) are locally independent of the efficiency conditions (25)-(26). The following three examples show why this need not be true.

Example 1 First, if $u_{i}(c)=\left(c^{1-\sigma}-1\right) /(1-\sigma)$ for some $\sigma>0$ and all $i$, then (31) is implied by the efficiency conditions (25)-(26). This implies that competitive equilibria are in fact efficient. For these preferences, the fact that the $\mathrm{D} u_{i}\left(c_{i, 3}\right) / \mathrm{D} u_{i}\left(c_{i, 2}\right)$ are the same across consumers implies that consumption growth between dates 2 and 3 is the same for all consumers. In turn, this implies that $\mathrm{D}^{2} u_{i}\left(c_{i, 3}\right) / \mathrm{D}^{2} u_{i}\left(c_{i, 2}\right)$ is also the same across consumers, which makes (31) redundant. Thus, in particular, the linear competitive equilibrium studied in Luttmer and Mariotti (2000) is efficient.

Example 2 Alternatively, consider arbitrary utility functions $u_{i}$ but suppose that $e_{2}=e_{3}$. Then efficiency in the 2-period exchange economy that starts at date 2 requires that $c_{i, 2}=c_{i, 3}$ for all consumers. Constant consumption across time for all consumers again makes (31) redundant.

Example 3 A third example arises when consumers are identical and have identical endowments. In this case, if no lotteries are used, then a symmetric equilibrium would clearly be efficient, although one need not necessarily exist.

We shall show that these examples of efficiency are special, either because of homotheticity, or because of non-generic endowments. If preferences are nowhere locally homothetic, then for generic endowments, condition (31) will be independent of the efficiency conditions (25)-(26). 


\subsection{Critical Points}

In order to compare efficient and equilibrium allocations, we need to rule out two types of critical points.

Local Homotheticity First, we rule out cases in which preferences are locally homothetic. This corresponds to situations in which the ratio:

$$
s_{i}(x)=\frac{\mathrm{D}^{3} u_{i}(x) \mathrm{D} u_{i}(x)}{\left[\mathrm{D}^{2} u_{i}(x)\right]^{2}}
$$

is constant over some range, i.e., preferences exhibit locally linear risk tolerance. Hence the following assumption.

Assumption $\mathbf{Z}$ The utility functions $u_{i}$ are such that $\mathrm{D} s_{i}$ is zero on a closed set of measure zero.

A weaker version of Assumption $\mathrm{Z}$ would require that the set of points at which $\mathrm{D} s_{i}$ vanishes is nowhere dense in $\mathbb{R}_{++}$. The results derived below hold under this alternative assumption provided "measure zero" is replaced by "nowhere dense and closed" in all the statements below. Define, for every $t$ :

$$
A_{t}=\left\{\left(e_{t}, c_{t}, e_{-t}\right) \in \Theta: \prod_{i=1}^{I} \mathrm{D} s_{i}\left(c_{i, t}\right)=0\right\},
$$

and:

$$
B_{t}=\left\{(e, c) \in \mathcal{P}: \prod_{i=1}^{I} \mathrm{D} s_{i}\left(c_{i, t}\right)=0\right\} .
$$

For every $t$, we have $\varphi_{t}^{-1}\left(B_{t}\right) \subset A_{t}$. Assumption $\mathrm{Z}$ implies that $A_{t}$ has measure zero in $\Theta$. Since $\varphi_{t}$ is a diffeomorphism, it then follows that $B_{t}$ has measure zero in $\mathcal{P}$, for every $t$. Thus, leaving out points from the efficient manifold at which some $\mathrm{D} s_{i}\left(c_{i, t}\right)$ vanishes amounts to leaving out a set of points that is of measure zero in the efficient manifold. Intuitively, the fact that $\varphi_{t}$ is a diffeomorphism implies that the efficient manifold has no tangent spaces of the form $\left\{(e, c): c_{i, t}=0\right\}$. The fact that $B_{t}$ has measure zero in $\mathcal{P}$ follows naturally from this and Assumption $\mathrm{Z}$.

For each $i$, let $C_{i}$ be the set of points where $\mathrm{D} s_{i}$ is not equal to zero, and let $C$ be the Cartesian product of the $C_{i}$. Write $\mathcal{P}^{*}$ for the intersection of $\mathcal{P}$ with $\mathbb{R}_{++}^{3} \times C^{3}$, and $\Theta^{*}$ for the intersection of $\Theta$ with $\mathbb{R}_{++} \times C \times \mathbb{R}_{++}^{2}$. Since the $\mathrm{D} s_{i}$ are continuous it follows that $C$ is a smooth submanifold of $\mathbb{R}_{++}^{I}$, of the same dimension. Similarly, $\mathcal{P}^{*}$ and $\Theta^{*}$ are submanifolds of $\mathcal{P}$ and $\Theta$, respectively, and of the same dimension as $\mathcal{P}$ and $\Theta$. As a result of Assumption $\mathrm{Z}, \mathcal{P}^{*}$ differs from $\mathcal{P}$ by a closed set of measure zero. For every $t, \varphi_{t}: \Theta^{*} \rightarrow \mathcal{P}^{*}$ is again a diffeomorphism.

Further Critical Points It turns out that eliminating points of the consumption spaces where preferences are locally homothetic is not enough to get our genericity 
result. By focusing on points in $C$ we can eliminate some additional critical points from the commodity space without eliminating non-negligible pieces from $\mathcal{P}$. For each $i$, define $r_{i}: \mathbb{R}_{++}^{3} \times C^{3} \rightarrow \mathbb{R}$ by:

$$
r_{i}(e, c)=s_{i}\left(c_{i, 2}\right)-s_{i}\left(c_{i, 3}\right),
$$

and consider the function $R_{i}: \Theta^{*} \rightarrow \mathbb{R}$ defined as:

$$
R_{i}(\theta)=r_{i}\left(\varphi_{1}(\theta)\right)
$$

The following lemma is proved in the Appendix.

Lemma 5 For each $i$, zero is a regular value of $R_{i}$.

Now, recall that $\Theta^{*}$ is a submanifold of $\Theta$ of the same dimension as $\Theta$, i.e., $I+2$. Since zero is a regular value of $R_{i}$, the Preimage Theorem implies that the zero set of $R_{i}$ is a submanifold of $\Theta^{*}$ of dimension $I+1$, and, since $\varphi_{1}$ is a diffeomorphism, its image under $\varphi_{1}$ forms a submanifold of $\mathcal{P}^{*}$ of lower dimension than $\mathcal{P}^{*}$. For every $i$, we can therefore eliminate from $\mathcal{P}^{*}$ the points $(e, c)=\varphi_{1}(\theta)$ that satisfy $R_{i}(\theta)=0$ for some $\theta \in \Theta^{*}$. Write $\mathcal{P}^{* *}$ for the resulting open subset of $\mathcal{P}$. By construction, $\mathcal{P}^{* *}$ is a submanifold of $\mathcal{P}$ of the same dimension as $\mathcal{P}$. Moreover, $\mathcal{P}^{* *}$ differs from $\mathcal{P}$ by a closed set of measure zero, and $s_{i}\left(c_{i, 2}\right)$ and $s_{i}\left(c_{i, 3}\right)$ never coincide for any $i$ on $\mathcal{P}^{* *}$.

\subsection{Efficient Equilibria are Non-Generic}

We are now ready to complete the proof of our generic inefficiency result. A convenient way to describe the set of efficient equilibrium allocations defined by (25)-(26) and (30) is obtained by eliminating the Pareto weights and shadow prices. This gives:

$$
\left[\begin{array}{c}
\mathrm{D} u_{i}\left(c_{i, 2}\right)-\phi \mathrm{D} u_{i}\left(c_{i, 1}\right) \\
\mathrm{D} u_{i}\left(c_{i, 3}\right)-\psi \mathrm{D} u_{i}\left(c_{i, 2}\right) \\
\mathrm{D}^{2} u_{i}\left(c_{i, 3}\right)-\xi \mathrm{D}^{2} u_{i}\left(c_{i, 2}\right)
\end{array}\right]=0
$$

for all $i$ and $t$, and some $(\phi, \psi, \xi) \in \mathbb{R}_{++}^{3}$, together with the feasibility conditions:

$$
e_{t}-\sum_{i=1}^{I} c_{i, t}=0
$$

for all $t$. Given a vector of aggregate endowments $e$, we have to solve for the consumption allocation $c$ and $(\phi, \psi, \xi)$. Note that (32)-(33) is a system of $3(I+1)$ equations and $3(I+1)$ unknowns. Differentiating the LHS of $(32)$ with respect to $\left(c_{i}, \phi, \psi, \xi\right)$ and scaling the $t^{\text {th }}$ row of the derivative by $\mathrm{D} u_{i}\left(c_{i, t}\right)$ yields:

$$
\left[\begin{array}{ll}
A_{i} & B
\end{array}\right]=\left[\begin{array}{cccccc}
-\frac{\mathrm{D}^{2} u_{i}\left(c_{i, 1}\right)}{\mathrm{D} u_{i}\left(c_{i, 1}\right)} & \frac{\mathrm{D}^{2} u_{i}\left(c_{i, 2}\right)}{\mathrm{D} u_{i}\left(c_{i, 2}\right)} & 0 & -\phi^{-1} & 0 & 0 \\
0 & -\frac{\mathrm{D}^{2} u_{i}\left(c_{i, 2}\right)}{\mathrm{D} u_{i}\left(c_{i, 2}\right)} & \frac{\mathrm{D}^{2} u_{i}\left(c_{i, 3}\right)}{\mathrm{D} u_{i}\left(c_{i, 3}\right)} & 0 & -\psi^{-1} & 0 \\
0 & -\frac{\mathrm{D}^{3} u_{i}\left(c_{i, 2}\right)}{\mathrm{D}^{2} u_{i}\left(c_{i, 2}\right)} & \frac{\mathrm{D}^{3} u_{i}\left(c_{i, 3}\right)}{\mathrm{D}^{2} u_{i}\left(c_{i, 3}\right)} & 0 & 0 & -\xi^{-1}
\end{array}\right]
$$


The derivative of the LHS of (32) and (33) therefore has the same rank as:

$$
\left[\begin{array}{cccccc}
0 & A_{1} & 0 & \cdots & 0 & B \\
0 & 0 & \ddots & 0 & \vdots & \vdots \\
\vdots & \vdots & \ddots & A_{I-1} & 0 & B \\
0 & 0 & \cdots & 0 & A_{I} & B \\
I_{3} & -I_{3} & \cdots & -I_{3} & -I_{3} & 0
\end{array}\right] .
$$

Suppose now that we restrict attention to economies in:

$$
W=\mathbb{R}_{++}^{3(I+1)} \backslash\left[\mathcal{P} \backslash \mathcal{P}^{* *}\right] .
$$

$W$ is submanifold of $\mathbb{R}_{++}^{3(I+1)}$ of dimension $3(I+1)$, and differing from $\mathbb{R}_{++}^{3(I+1)}$ by a closed set of measure zero. The determinant of $A_{i}$ is given by:

$$
\frac{\mathrm{D}^{2} u_{i}\left(c_{i, 1}\right)}{\mathrm{D} u_{i}\left(c_{i, 1}\right)} \frac{\mathrm{D}^{2} u_{i}\left(c_{i, 2}\right)}{\mathrm{D} u_{i}\left(c_{i, 2}\right)} \frac{\mathrm{D}^{2} u_{i}\left(c_{i, 3}\right)}{\mathrm{D} u_{i}\left(c_{i, 3}\right)}\left[s_{i}\left(c_{i, 3}\right)-s_{i}\left(c_{i, 2}\right)\right] .
$$

The strict concavity of $u_{i}$ implies that this is zero if and only if $s_{i}\left(c_{i, 3}\right)=s_{i}\left(c_{i, 2}\right)$. But this cannot happen on $W$ for any $i$. Thus all the $A_{i}$ are non-singular on $W$. This implies that (34) has full rank. Therefore zero is a regular value of the map defined by (32)-(33). The Transversality Theorem implies that for generic endowments $e$, efficient equilibrium allocations $c$ are isolated. We have proved the following proposition.

Proposition 5 Under Assumptions S and Z, the sets of date-1 Pareto efficient and equilibrium allocations intersect only at isolated points, except for economies with endowments in a closed set of measure zero.

The underlying intuition for the importance of homotheticity is easy to see. Note that (29) can be expressed using the marginal propensity to consume out of date-2 wealth as:

$$
\frac{p_{2}}{p_{1}}=\left(\mathrm{D}_{w} c_{i, 2}\left(p, w_{2}\right) \delta_{1}+\left(1-\mathrm{D}_{w} c_{i, 2}\left(p, w_{2}\right)\right) \frac{\delta_{2}}{\delta_{1}}\right) \frac{\mathrm{D} u_{i}\left(c_{i, 2}\left(p, w_{2}\right)\right)}{\mathrm{D} u_{i}\left(c_{i, 1}\left(p, w_{1}\right)\right)} .
$$

This is the generalized Euler equation of Harris and Laibson (2001). Date-1 efficiency requires that the date- 2 consumption functions of all consumers have the same slope in equilibrium. Proposition 5 shows that this can hold generically only for the linear consumption functions implied by homothetic preferences.

\section{Concluding Remarks}

Renegotiation-proofness is a benchmark for efficiency in an economy in which it is not possible to commit not to renegotiate. One would expect renegotiation-proof 
allocations to arise in an environment in which a contract is enforced unless all parties to the contract agree to re-write it, and in which bargaining is efficient. Our results show that a sequence of competitive markets with or without lotteries need not achieve this benchmark of efficiency. ${ }^{10}$ An interesting open question is: are there decentralized mechanisms, other than a complete set of date- 1 markets, that do?

We have focussed on exchange economies. The example of Krusell, Kuruşçu, and Smith (2001) shows that the competitive equilibrium in a production economy with identical consumers and homothetic preferences can yield a higher level of utility to consumers at the initial date than does any renegotiation-proof allocation. Thus renegotiation-proof allocations need no longer be Pareto efficient from the perspective of consumers at the initial date. Instead, competitive markets generate a form of commitment that makes these consumers better-off than when they have access to efficient centralized bargaining procedures. However, the use of homothetic preferences in Krusell, Kuruşçu, and Smith (2001) rules out the sort of inefficiency of competitive markets that can occur even in an exchange economy. Clearly, a further investigation of production economies is warranted.

Most of our results were shown for three-period economies. The benefit of this assumption is that the date- 2 consumer faces a standard concave decision problem. This ensures that his optimal decision rules are continuous, and that there is no loss of generality in focusing on Markov perfect equilibria for which current wealth is the state variable. It is unclear whether this Markov structure can be carried over into more general multiperiod economies (see Peleg and Yaari (1973)), although allowing for randomization or lotteries, as we do here, may help in this respect. Our preliminary investigations suggest that considering the whole set of subgame perfect equilibria of the intrapersonal game (in line with Goldman (1980)) may also be a fruitful avenue of research.

\section{A Existence of a Competitive Equilibrium}

Proof of Lemma 2. Note first that, since consumer $i$ cannot spend his wealth twice, and $u_{i}$ is increasing, we obtain, for all $\left(p, w_{2}\right) \in P \times \mathbb{R}_{++}$:

$$
V_{i}\left(p, w_{2}\right) \leq\left(\delta_{1}+\delta_{2}\right) u_{i}\left(w_{2}\left(1+\max _{p \in P}\left\{\frac{p_{2}}{p_{3}}\right\}\right)\right) .
$$

Thus, by Assumption U, $\lim _{w_{2} \rightarrow \infty} V_{i}\left(p, w_{2}\right) / w_{2}=0$, and $\lim _{w_{2} \rightarrow 0^{+}} V_{i}\left(p, w_{2}\right)=-\infty$ whenever $u_{i}$ is unbounded below. For any given $\left(p, w_{1}\right) \in P \times W_{i, 1}$, the date-1

\footnotetext{
${ }^{10}$ This is in contrast to the situation in economies with private information where lotteries can achieve constrained efficient allocations (see Prescott and Townsend (1984) and Kehoe, Levine and Prescott (2002)).
} 
consumer is faced with the following decision problem:

$$
\sup _{\left(c_{1}, \mu\right) \in \mathbb{R}_{+} \times \Delta\left(\mathbb{R}_{+}\right)}\left\{u_{i}\left(c_{1}\right)+\int V_{i}\left(p, w_{2}\right) \mathrm{d} \mu\left(w_{2}\right): p_{1} c_{1}+p_{2} \int w_{2} \mathrm{~d} \mu\left(w_{2}\right) \leq p_{1} w_{1}\right\} .
$$

This can also be represented as a two-step decision problem:

$$
\sup _{\left(c_{1}, \bar{w}_{2}\right) \in \mathbb{R}_{+}^{2}}\left\{u_{i}\left(c_{1}\right)+v_{i}\left(p, \bar{w}_{2}\right): p_{1} c_{1}+p_{2} \bar{w}_{2} \leq p_{1} w_{1}\right\}
$$

where the value function $v_{i}: P \times \mathbb{R}_{+} \rightarrow \underline{\mathbb{R}}$ is given by the least concave supremum of $V_{i}(p, \cdot)$ :

$$
v_{i}\left(p, \bar{w}_{2}\right)=\sup _{\mu \in \Delta\left(\mathbb{R}_{+}\right)}\left\{\int V_{i}\left(p, w_{2}\right) \mathrm{d} \mu\left(w_{2}\right): \int w_{2} \mathrm{~d} \mu\left(w_{2}\right)=\bar{w}_{2}\right\},
$$

It follows from Caratheodory's Theorem that $v_{i}$ can in turn be represented as:

$$
v_{i}\left(p, \bar{w}_{2}\right)=\sup _{(x, y) \in \mathbb{R}_{+}^{2}}\left\{\left(\frac{y-\bar{w}_{2}}{y-x}\right) V_{i}(p, x)+\left(\frac{\bar{w}_{2}-x}{y-x}\right) V_{i}(p, y): x \leq \bar{w}_{2} \leq y\right\}
$$

(see Rockafellar (1970, Corollary 17.1.5)). Let $\bar{w}_{2}^{\max }=\max _{p \in P}\left\{p_{1} / p_{2}\right\} \max W_{i, 1}$. We first prove that there exists some $y^{\max } \in \mathbb{R}_{++}$such that, for any $\left(p, \bar{w}_{2}\right) \in$ $P \times\left(0, \bar{w}_{2}^{\max }\right]$, any sequence $\left\{\left(x_{n}, y_{n}\right)\right\}$ that approximates $(39)$ can be replaced by a sequence $\left\{\left(x_{n}, y_{n}^{\prime}\right)\right\}$ such that $\left\{y_{n}^{\prime}\right\}$ is bounded above by $y^{\max }$. Fix some $w_{2}^{*}>\bar{w}_{2}^{\max }$. Without loss of generality, we may assume that $V_{i}\left(p, w_{2}^{*}\right)$ is positive and thus bounded away from zero for all $p \in P$. By (35), there exists some $y^{\max }>w_{2}^{*}$ such that:

$$
\min \left\{\frac{V_{i}\left(p, w_{2}^{*}\right)}{w_{2}^{*}}, \min _{x \in\left[0, \bar{w}_{2}^{\max }\right]}\left\{\frac{V_{i}\left(p, w_{2}^{*}\right)-V_{i}(p, x)}{w_{2}^{*}-x}\right\}\right\} \geq \frac{V_{i}(p, y)}{y-w_{2}^{*}}
$$

for all $(p, y) \in P \times\left[y^{\max }, \infty\right)$. Consider a sequence $\left\{\left(x_{n}, y_{n}\right)\right\}$ that approximates $(39)$ and suppose that for some $n, y_{n}>y^{\max }$. Change the lottery with support $\left\{x_{n}, y_{n}\right\}$ and expectation $\bar{w}_{2}$ to a lottery with support $\left\{x_{n}, w_{2}^{*}\right\}$ and the same expectation. The resulting change in the objective of (39) is given by:

$$
\left(\bar{w}_{2}-x_{n}\right)\left(\frac{V_{i}\left(p, w_{2}^{*}\right)}{w_{2}^{*}-x_{n}}-\frac{V_{i}\left(p, y_{n}\right)}{y_{n}-x_{n}}-\frac{\left(y_{n}-w_{2}^{*}\right) V_{i}\left(p, x_{n}\right)}{\left(y_{n}-x_{n}\right)\left(w_{2}^{*}-x_{n}\right)}\right),
$$

and this is strictly positive by (40), independently of the sign of $V_{i}\left(p, x_{n}\right)$. If $u_{i}$ is bounded below, this proves the result since one can choose $C_{i, 1}=\left[0, \max W_{i, 1}\right]$ and $W_{i, 2}=\left[0, y^{\max }\right]$, and (37)-(38) is reduced to a compact continuous decision problem. Suppose now that $u_{i}$ is not bounded below. It is easy to see that the value of (37) must be bounded away from $-\infty$ on $P \times W_{i, 1}$, and, from (35), that one need only consider $c_{1} \in\left[c_{1}^{\min }, \max W_{i, 1}\right]$ and $\bar{w}_{2} \in\left[\bar{w}_{2}^{\min }, \bar{w}_{2}^{\max }\right]$ for some $c_{1}^{\min }>0$ and $\bar{w}_{2}^{\min }>0$. We now 
prove that there exists some $x^{\min } \in \mathbb{R}_{++}$such that, for any $\left(p, \bar{w}_{2}\right) \in P \times\left[\bar{w}_{2}^{\min }, \bar{w}_{2}^{\max }\right]$, any sequence $\left\{\left(x_{n}, y_{n}\right)\right\}$ (with $\left.y_{n} \leq y^{\max }\right)$ that approximates (39) can be replaced by a sequence $\left\{\left(x_{n}^{\prime}, y_{n}\right)\right\}$ such that $\left\{x_{n}^{\prime}\right\}$ is bounded below by $x^{\text {min }}$. Fix some $w_{2}^{* *}<$ $\bar{w}_{2}^{\min }$. Without loss of generality, we may assume that $V_{i}\left(p, w_{2}^{* *}\right)$ is negative and thus bounded away from zero for all $p \in P$. By (35), there exists some $x^{\text {min }}<w_{2}^{* *}$ such that:

$$
\min \left\{\frac{V_{i}\left(p, w_{2}^{* *}\right)}{\bar{w}_{2}^{\min }-w_{2}^{* *}}, \min _{y \in\left[\bar{w}_{2}^{\min }, y^{\max }\right]}\left\{\frac{V_{i}\left(p, w_{2}^{* *}\right)-V_{i}(p, y)}{y-w_{2}^{* *}}\right\}\right\} \geq \frac{V_{i}(p, x)}{y^{\max }-x}
$$

for all $(p, x) \in P \times\left(0, x^{\mathrm{min}}\right]$. Consider a sequence $\left\{\left(x_{n}, y_{n}\right)\right\}$ that approximates (39) and suppose that for some $n, x_{n}<x^{\min }$. Change the lottery with support $\left\{x_{n}, y_{n}\right\}$ and expectation $\bar{w}_{2}$ to a lottery with support $\left\{w_{2}^{* *}, y_{n}\right\}$ and the same expectation. The resulting change in the objective of (39) is given by:

$$
\left(y_{n}-\bar{w}_{2}\right)\left(\frac{V_{i}\left(p, w_{2}^{* *}\right)}{y_{n}-w_{2}^{* *}}-\frac{V_{i}\left(p, x_{n}\right)}{y_{n}-x_{n}}-\frac{\left(w_{2}^{* *}-x_{n}\right) V_{i}\left(p, y_{n}\right)}{\left(y_{n}-x_{n}\right)\left(y_{n}-w_{2}^{* *}\right)}\right)
$$

which is strictly positive by (41), independently of the sign of $V_{i}\left(p, y_{n}\right)$. This proves the result, since one can choose $C_{i, 1}=\left[c_{1}^{\min }, \max W_{i, 1}\right]$ and $W_{i, 2}=\left[x^{\min }, y^{\max }\right]$, and (37)-(38) is reduced to a compact continuous decision problem.

\section{B Smooth Preferences}

Proof of Lemma 4. Since $g$ is a one-to-one mapping, we need only check that it is a local diffeomorphism. Taking the gradient of (25)-(26) and using the Implicit Function Theorem yields:

$$
\left[\begin{array}{c}
\mathrm{D} c_{t}\left(e_{t}, \lambda\right) \\
\mathrm{D} p_{t}\left(e_{t}, \lambda\right)
\end{array}\right]=-\left[\begin{array}{cc}
\operatorname{diag}\left[\lambda \mathrm{D}^{2} u\right] & -\iota \\
-\iota^{\prime} & 0
\end{array}\right]^{-1}\left[\begin{array}{cc}
0 & \operatorname{diag}[\mathrm{D} u] \\
1 & 0
\end{array}\right]
$$

where $\iota$ denotes the unit vector of $\mathbb{R}^{I}$. Write $h=\left[h_{1}, \ldots, h_{I}\right]^{\prime}$ with:

$$
h_{i}=\frac{\mathrm{D} u_{i}\left(c_{i, t}\right)}{\mathrm{D}^{2} u_{i}\left(c_{i, t}\right)}
$$

evaluated at the date- $t$ allocation specified by $g\left(e_{t}, \lambda\right)$. Using (42), one may then verify that $\mathrm{D} g\left(e_{t}, \lambda\right)$ can be expressed as:

$$
\mathrm{D} g\left(e_{t}, \lambda\right)=\left[\begin{array}{cc}
1 & 0 \\
\left(\iota^{\prime} h\right)^{-1} h & -\operatorname{diag}[h]+\left(\iota^{\prime} h\right)^{-1} h h^{\prime}
\end{array}\right]\left[\begin{array}{cc}
1 & 0 \\
0 & \operatorname{diag}[\lambda]
\end{array}\right]^{-1} .
$$

By the Inverse Function Theorem, it is enough to prove that $\mathrm{D} g\left(e_{t}, \lambda\right)$ induces an isomorphism between the tangent space of $\mathbb{R} \times \Delta_{I}$ and $F$. For any given $(\bar{x}, \bar{y}) \in F$, this amounts to examining the solutions in $\left\{y \in \mathbb{R}^{I}: \iota^{\prime} y=0\right\}$ to:

$$
\bar{a} \equiv \bar{y}-\bar{x}\left(\iota^{\prime} h\right)^{-1} h=\left(-\operatorname{diag}[h]+\left(\iota^{\prime} h\right)^{-1} h h^{\prime}\right) \operatorname{diag}[\lambda]^{-1} y .
$$


The one-dimensional linear space of solutions can be parameterized as $y(\zeta)=\zeta \lambda+y_{\bar{a}}$, where $\lambda^{\prime} y_{\bar{a}}=0$. Imposing the additional restriction that $\iota^{\prime} \bar{a}=0$ implies $\zeta=-\iota^{\prime} y_{\bar{a}}$. Therefore $\mathrm{D} g\left(e_{t}, \lambda\right)$ has a unique inverse when restricted to the tangent space of $\mathbb{R} \times \Delta_{I}$, which implies the result.

Proof of Proposition 4. Necessary conditions for a competitive equilibrium allocation $c$ without lotteries are given by (30) together with the budget constraints:

$$
\sum_{t=1}^{3} p_{t}\left(e_{i, t}-c_{i, t}\right)=0
$$

for all $i$, and the market clearing conditions:

$$
\sum_{i=1}^{I}\left(e_{i, t}-c_{i, t}\right)=0
$$

for all $t$. By Walras' Law, one of the market clearing conditions or budget constraints is redundant. Homogeneity of the budget constraints implies that $p$ can be normalized in an arbitrary way. We normalize prices to satisfy $p^{\prime} p / 2=1$. Write $K(e, c, \lambda, p)=0$ for (30)-(44)-(45). The derivative $\mathrm{D} K(e, c, \lambda, p)$ is given by:

$$
\left[\begin{array}{cccccccccc}
0 & \cdots & 0 & \lambda_{1} \mathrm{D} m_{1}\left(c_{1}\right) & 0 & 0 & m_{1}\left(c_{1}\right) & 0 & 0 & -I_{3} \\
\vdots & \ddots & \vdots & 0 & \ddots & 0 & 0 & \ddots & 0 & \vdots \\
0 & \cdots & 0 & 0 & 0 & \lambda_{I} \mathrm{D} m_{I}\left(c_{I}\right) & 0 & 0 & m_{I}\left(c_{I}\right) & -I_{3} \\
p^{\prime} & 0 & 0 & -p^{\prime} & 0 & 0 & 0 & \cdots & 0 & \left(e_{1}-c_{1}\right)^{\prime} \\
0 & \ddots & 0 & 0 & \ddots & 0 & \vdots & \ddots & \vdots & \vdots \\
0 & 0 & p^{\prime} & 0 & 0 & -p^{\prime} & 0 & \cdots & 0 & \left(e_{I}-c_{I}\right)^{\prime} \\
I_{3} & \cdots & I_{3} & -I_{3} & \cdots & -I_{3} & 0 & \cdots & 0 & 0 \\
0 & \cdots & 0 & 0 & \cdots & 0 & 0 & \cdots & 0 & p^{\prime}
\end{array}\right] .
$$

For $\mathrm{D} K(e, c, \lambda, p)$ to have full rank (taking into account Walras' law), it is sufficient that for all $i$, the $3 \times 4$ matrix:

$$
\left[\begin{array}{ll}
m_{i}\left(c_{i}\right) & \mathrm{D} m_{i}\left(c_{i}\right)
\end{array}\right]
$$

be of rank 3. It is easy to verify that, for this to hold, we need the following matrix to have rank 2 :

$$
\left[\begin{array}{ccc}
1 & 1+h_{i}\left(c_{i, 2}, c_{i, 3}\right)\left(s_{i}\left(c_{i, 2}\right)-2\right) & -h_{i}\left(c_{i, 2}, c_{i, 3}\right)\left(s_{i}\left(c_{i, 3}\right)-2\right) \\
1 & h_{i}\left(c_{i, 2}, c_{i, 3}\right)\left(s_{i}\left(c_{i, 2}\right)-2\right) & 1-h_{i}\left(c_{i, 2}, c_{i, 3}\right)\left(s_{i}\left(c_{i, 3}\right)-2\right)
\end{array}\right],
$$

where the function $h_{i}$ is defined by:

$$
h_{i}(x, y)=\frac{\left(\delta_{2}-\delta_{1}^{2}\right) f_{i}(x, y) \frac{\left[\mathrm{D} u_{i}(y)\right]^{2}}{\mathrm{D}^{2} u_{i}(y)}}{\left(\delta_{1} \frac{\left[\mathrm{D} u_{i}(x)\right]^{2}}{\mathrm{D}^{2} u_{i}(x)}+\delta_{2} \frac{\left[\mathrm{D} u_{i}(y)\right]^{2}}{\mathrm{D}^{2} u_{i}(y)}\right)^{2}}
$$


This is indeed the case, since neither of the second two columns of (47) can be zero or proportional to the first column. Since $K(e, c, \lambda, p)=0$ implies that $\mathrm{D} K(e, c, \lambda, p)$ has full rank (taking into account Walras' Law), the Transversality Theorem implies that for generic endowments, zero is a regular value of $K(e, \cdot, \cdot, \cdot)$ and therefore that any solution to (30)-(44)-(45) is locally unique.

Proof of Lemma 5. Note that $\mathrm{D} R_{i}(\theta)=\mathrm{D} r_{i}(e, c) \mathrm{D} \varphi_{1}(\theta)$ for $(e, c)=\varphi_{1}(\theta)$ and $\theta=\left(e_{1}, c_{1}, e_{-1}\right)$. Since $c \in C$ whenever $\theta \in \Theta^{*}, \operatorname{D} r_{i}(e, c) \neq 0$. Consider varying the $e_{-1}$-component of $\theta$. Since $\left(e_{1}, c_{1}\right)$ is fixed, $\lambda=l\left(c_{1}\right)$ must be fixed. Thus we are to investigate changes in $\left(c_{i, 2}, c_{i, 3}\right)$ as $\left(e_{2}, e_{3}\right)$ varies for fixed $\lambda$. Efficiency requires that consumption of all consumers co-moves strictly with the aggregate. Indeed, it follows from (43) that $\mathrm{D}_{e_{t}} c_{i, t}\left(e_{t}, \lambda\right)=\left(\iota^{\prime} h\right)^{-1} h_{i}$, where $h_{i}<0$. Thus, by varying $\left(e_{2}, e_{3}\right)$ in arbitrary directions, one can vary $\left(c_{i, 2}, c_{i, 3}\right)$ in arbitrary directions for each $i$. This means that one can find a linear combination of the columns of $\mathrm{D} \varphi_{1}(\theta)$ that is not orthogonal to $\mathrm{D} r_{i}(e, c)$. It follows that $\mathrm{D} R_{i}(\theta) \neq 0$, as claimed.

\section{REFERENCES}

[1] Aliprantis, C.D., and K.C. Border (1999): Infinite Dimensional Analysis: A Hitchhiker's Guide, Second Edition, Springer Verlag, New York.

[2] Arrow, K.J. (1964): "The Role of Securities in the Optimal Allocation of RiskBearing," Review of Economic Studies, Vol. 31, No. 2 (April), 91-96.

[3] Barro, R.J. (1999): "Ramsey Meets Laibson in the Neoclassical Growth Model," Quarterly Journal of Economics, Vol. CXIV, No. 4 (November), 1125-1152.

[4] Benabou, R., and J. Tirole (2002): "Self-Confidence and Personal Motivation," forthcoming, Quarterly Journal of Economics.

[5] Carrillo, J.D., and T. Mariotti (2000): "Strategic Ignorance as a Self-Disciplining Device," Review of Economic Studies, Vol. 67, No. 3 (July), 529-544.

[6] Debreu, G. (1982): "Existence of Competitive Equilibrium," in Handbook of Mathematical Economics, Volume II, K.J. Arrow and M.D. Intriligator, Editors, North-Holland, Amsterdam.

[7] Friedman, M., and L.J. Savage (1948): "The Utility Analysis of Choices Involving Risk," Journal of Political Economy, Vol. 56, No. 4 (August), 279-304.

[8] Goldman, S.M. (1980): "Consistent Plans," Review of Economic Studies, Vol. 47, No. 3 (April), 533-537.

[9] Gul, F., and W. Pesendorfer (1999): "Self-Control and the Theory of Consumption," Princeton University. 
[10] Gul, F., and W. Pesendorfer (2001): "Temptation and Self-Control," Econometrica, Vol. 69, No. 6 (November), 1403-1435.

[11] Harris, C., and D. Laibson (2001): "Dynamic Choices of Hyperbolic Consumers," Econometrica, Vol. 69, No. 4 (July), 935-957.

[12] Kehoe, T.J., D.K. Levine, and E.C. Prescott (2002): "Lotteries, Sunspots, and Incentive Constraints," forthcoming, Journal of Economic Theory.

[13] Kocherlakota, N. (2001): "Looking for Evidence of Time-Inconsistent Preferences in Asset Market Data," Federal Reserve Bank of Minneapolis Quarterly Review, Vol. 25, No. 3 (Summer), 13-24.

[14] Krusell, P., and A.A. Smith (1999): "Consumption and Savings Decisions with Quasi-Geometric Discounting," mimeo, Carnegie Mellon University.

[15] Krusell, P., B. Kuruşçu, and A.A. Smith (2001): "Equilibrium Welfare and Government Policy with Quasi-Geometric Discounting," forthcoming, Journal of Economic Theory.

[16] Laibson, D. (1997): "Golden Eggs and Hyperbolic Discounting," Quarterly Journal of Economics, Vol. CXII, No. 2 (May), 443-477.

[17] Luttmer, E.G.J., and T. Mariotti (2000): "Subjective Discounting in an Exchange Economy," London School of Economics and CEPR.

[18] Luttmer, E.G.J., and T. Mariotti (2000b): "Non-Recursive Homothetic Preferences," in progress.

[19] O'Donoghue, T., and M. Rabin (1999a): "Doing it Now or Later," American Economic Review, Vol. 89, No. 1 (March), 103-124.

[20] O’Donoghue, T., and M. Rabin (1999b): "Incentives for Procrastinators," Quarterly Journal of Economics, Vol. CXIV, No. 4 (August), 769-816.

[21] Peleg, B., and M. Yaari (1973): "On the Existence of a Consistent Course of Actions when Tastes are Changing," Review of Economic Studies, Vol. 40, No. 3 (July), 391-401.

[22] Phelps, E.S., and R.A. Pollak (1968): "On Second-Best National Saving and Game-Equilibrium Growth," Review of Economic Studies, Vol. 35, No. 2 (April), 185-199.

[23] Pollak, R.A. (1968): "Consistent Planning," Review of Economic Studies, Vol. 35, No. 2 (April), 201-208. 
[24] Prescott, E.C., and R.M. Townsend (1984): "Pareto Optima and Competitive Equilibria with Adverse Selection and Moral Hazard," Econometrica, Vol. 52, No. 1 (January), 21-45.

[25] Rockafellar, R.T. (1970): Convex Analysis, Princeton University Press, Princeton.

[26] Strotz, R.H. (1956): "Myopia and Inconsistency in Dynamic Utility Maximization," Review of Economic Studies, Vol. 23, No. 3, 165-180. 